\title{
High-throughput screening approaches and combinatorial development of biomaterials using microfluidics
}

Citation for published version (APA):

Barata, D., van Blitterswijk, C., \& Habibovic, P. (2016). High-throughput screening approaches and combinatorial development of biomaterials using microfluidics. Acta Biomaterialia, 34, 1-20. https://doi.org/10.1016/j.actbio.2015.09.009

Document status and date:

Published: 01/04/2016

DOI:

10.1016/j.actbio.2015.09.009

Document Version:

Publisher's PDF, also known as Version of record

Document license:

Taverne

Please check the document version of this publication:

- A submitted manuscript is the version of the article upon submission and before peer-review. There can be important differences between the submitted version and the official published version of record.

People interested in the research are advised to contact the author for the final version of the publication, or visit the DOI to the publisher's website.

- The final author version and the galley proof are versions of the publication after peer review.

- The final published version features the final layout of the paper including the volume, issue and page numbers.

Link to publication

\footnotetext{
General rights rights.

- You may freely distribute the URL identifying the publication in the public portal. please follow below link for the End User Agreement:

www.umlib.nl/taverne-license

Take down policy

If you believe that this document breaches copyright please contact us at:

repository@maastrichtuniversity.nl

providing details and we will investigate your claim.
}

Copyright and moral rights for the publications made accessible in the public portal are retained by the authors and/or other copyright owners and it is a condition of accessing publications that users recognise and abide by the legal requirements associated with these

- Users may download and print one copy of any publication from the public portal for the purpose of private study or research.

- You may not further distribute the material or use it for any profit-making activity or commercial gain

If the publication is distributed under the terms of Article $25 \mathrm{fa}$ of the Dutch Copyright Act, indicated by the "Taverne" license above, 
Review article

\title{
High-throughput screening approaches and combinatorial development of biomaterials using microfluidics
}

\author{
David Barata, Clemens van Blitterswijk ${ }^{1}$, Pamela Habibovic ${ }^{*, 1}$ \\ Department of Tissue Regeneration, University of Twente, P.O. Box 217, 7500 AE Enschede, The Netherlands
}

\section{A R T I C L E I N F O}

\section{Article history:}

Received 1 June 2015

Received in revised form 7 September 2015

Accepted 8 September 2015

Available online 8 September 2015

\section{Keywords:}

Microfluidics

Biomedical research

High-throughput screening

Biomaterials

Organ-on-chip

\begin{abstract}
A B S T R A C T
From the first microfluidic devices used for analysis of single metabolic by-products to highly complex multicompartmental co-culture organ-on-chip platforms, efforts of many multidisciplinary teams around the world have been invested in overcoming the limitations of conventional research methods in the biomedical field. Close spatial and temporal control over fluids and physical parameters, integration of sensors for direct read-out as well as the possibility to increase throughput of screening through parallelization, multiplexing and automation are some of the advantages of microfluidic over conventional, 2D tissue culture in vitro systems. Moreover, small volumes and relatively small cell numbers used in experimental set-ups involving microfluidics, can potentially decrease research cost. On the other hand, these small volumes and numbers of cells also mean that many of the conventional molecular biology or biochemistry assays cannot be directly applied to experiments that are performed in microfluidic platforms. Development of different types of assays and evidence that such assays are indeed a suitable alternative to conventional ones is a step that needs to be taken in order to have microfluidics-based platforms fully adopted in biomedical research. In this review, rather than providing a comprehensive overview of the literature on microfluidics, we aim to discuss developments in the field of microfluidics that can aid advancement of biomedical research, with emphasis on the field of biomaterials. Three important topics will be discussed, being: screening, in particular high-throughput and combinatorial screening; mimicking of natural microenvironment ranging from 3D hydrogel-based cellular niches to organ-on-chip devices; and production of biomaterials with closely controlled properties. While important technical aspects of various platforms will be discussed, the focus is mainly on their applications, including the state-of-the-art, future perspectives and challenges.
\end{abstract}

\section{Statement of Significance}

Microfluidics, being a technology characterized by the engineered manipulation of fluids at the submillimeter scale, offers some interesting tools that can advance biomedical research and development. Screening platforms based on microfluidic technologies that allow high-throughput and combinatorial screening may lead to breakthrough discoveries not only in basic research but also relevant to clinical application. This is further strengthened by the fact that reliability of such screens may improve, since microfluidic systems allow close mimicking of physiological conditions. Finally, microfluidic systems are also very promising as micro factories of a new generation of natural or synthetic biomaterials and constructs, with finely controlled properties.

(c) 2015 Acta Materialia Inc. Published by Elsevier Ltd. All rights reserved.

\footnotetext{
Part of the High Throughput Approaches to Screening Biomaterials Special Issue, edited by Kristopher Kilian and Prabhas Moghe.

* Corresponding author.

E-mail address: p.habibovic@maastrichtuniversity.nl (P. Habibovic).

${ }^{1}$ Current affiliation: Maastricht University, MERLN Institute for Technology-Inspired Regenerative Medicine, P.O. Box 616, 6200 MD Maastricht, The Netherlands.
} 


\section{Contents}

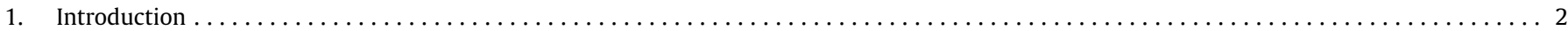

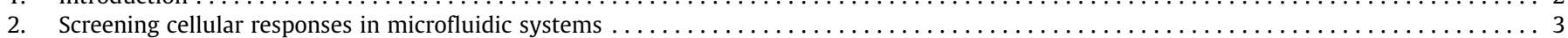

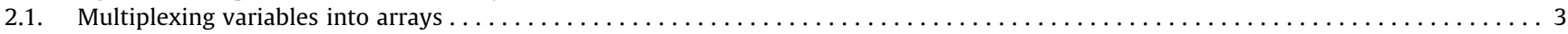

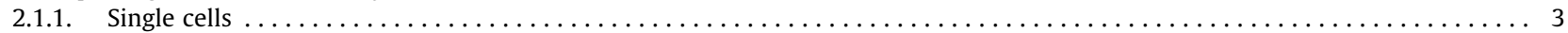

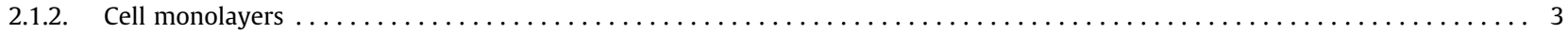

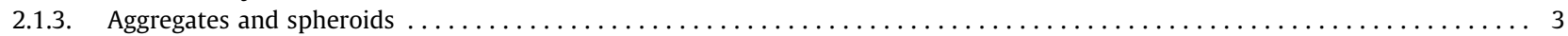

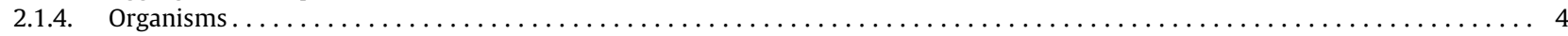

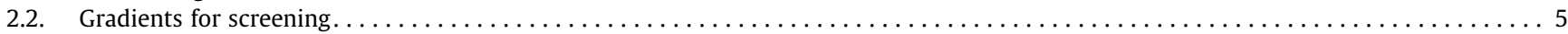

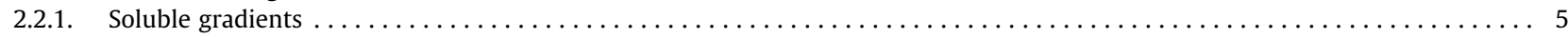

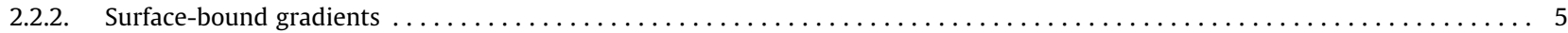

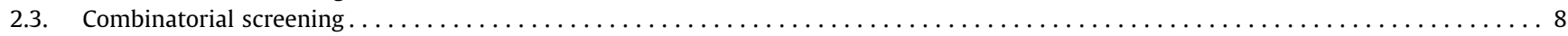

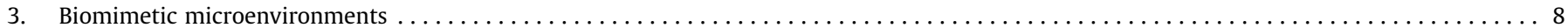

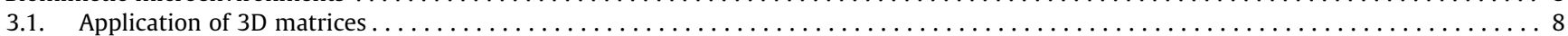

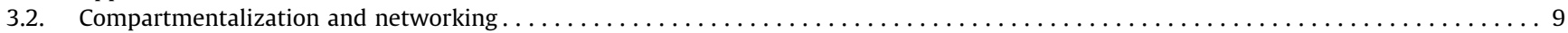

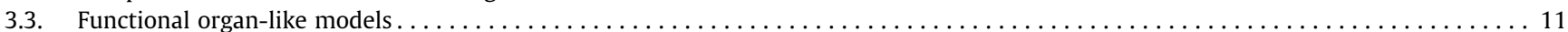

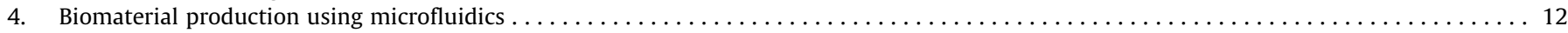

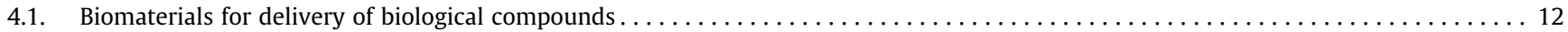

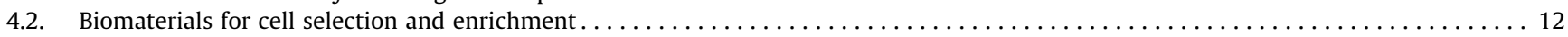

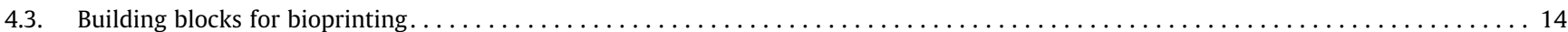

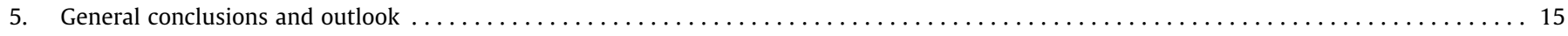

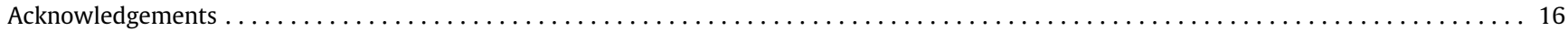

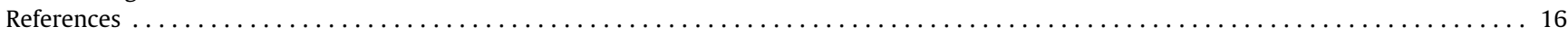

\section{Introduction}

It is now becoming increasingly recognized that in vitro cell culture experimental set-ups in the conventional tissue culture plastics fall short in mimicking the natural in vivo microenvironment, which is considered one of the reasons for their limited predictive value. In addition to efforts required to overcome this issue, an increasing need exists for higher throughput of screening in the biomedical field, with the aim to accelerate the development of new and improved medical treatments against lower costs. In the field of pharmacology, high-throughput screening approaches were implemented relatively early, however, a large gap has been observed between the in vitro findings and the in vivo efficiency of the treatment, which is, for at least in a part, due to the use of oversimplistic conventional cell culture systems [1,2]. This gap becomes even larger when biomaterials are introduced into the system. Indeed, conventional cell culture platforms were developed to study cell-cell interactions and cell responses to soluble stimuli such as growth factors, antibiotics, small molecules, etc. Interestingly, such platforms were implemented into biomaterials research field without significant modifications. As a consequence, many have shown that results on cell-material interactions obtained in such simplistic systems are also poorly representative of the interactions that occur in vivo [3]. These issues with research systems having poor predictability will undoubtedly continue to exist, since state-of-the-art solutions for clinical problems, such as regenerative strategies for damaged and diseased organs and tissues, are gaining on complexity. Indeed, modern regenerative solutions often include combined contributions from biomaterials of different types, cell- and tissue constructs, growth factors, etc. On the other hand, our society is ageing, requiring the efficiency of discovery of clinical treatments to be maintained at a high level. To keep up with these scientific and societal developments, it is therefore evident that efforts need to be invested in the development of research systems that allow both faster and more reliable screening for biomedical applications.

In the past 10 years, the wealth of developments in the field of microfluidics has helped to establish a new set of standards in the study of basic biological phenomena. Microfluidics is defined as the science and technology of systems that process and manipulate small $\left(10^{-9}-10^{-18} \mathrm{~L}\right)$ amounts of fluids by using channels with dimensions from tens to hundreds of micrometers [4]. Platforms based on microfluidics offer important advantages over classical in vitro cell culture systems such as close temporal and spatial control over fluids and physical parameters, integration of sensors for direct readout, and the possibility to increase throughput of screening by utilizing parallelization, multiplexing and automation. Furthermore, the micrometer scale makes microfluidic systems unique for having features in the range of a single cell size, which can be highly valuable in fundamental biological resarch, provided that also readouts are scaled down and their sensitivity reaches single cell resolution. Nevertheless, the validity of such assays, or the evidence that they are at least as reliable as conventional assays is needed for microfluidic platforms to be explored to the maximum extent. Alternatively to development of new assays, conventional analytical tools can be rendered applicable to microfluidic systems by means of customized interfacing [5].

Apart from the assays, the platforms as such, including the materials they are made from, and methods to produce them, need to prove their value for biomedical research. In early microfluidic systems for biomedical applications, rigid, inert materials such as silicon and glass, directly inherited from the field of microelectronics, reigned. However, current technology now allows the use of biopolymers that can be microfabricated to detail, tuned in their properties (e.g. stiffness, porosity, dielectric properties, hydrophilicity) by chemical changes, and biochemically decorated to better mimic the natural microenvironment [6]. These include photo- or heat-curable polymers such as SU-8 epoxy, polyimide photoresist, poly-dimethylsiloxane (PDMS) elastomer, as well as thermoplasts such as polymethylmethacrylate, polycarbonate, polystyrene, cyclic-olefin-copolymers and Teflon. Also the everlasting discussion between the PDMS-land engineers and polystyrenia kingdom biologists [7] has become further democratised, as a consequence of an exponentially increasing availability of complex materials that can be embedded in microfluidic devices, the on-demand delivery of smart hydrogels, and the nanometer-scale resolution printability of new scaffolding polymers and bioinorganics.

In this review, we aim to provide an overview of advances in the field of microfluidics that can aid biomedical research, with special emphasis on the field of biomaterials. We will do so by describing relevant examples of platforms that are developed with the aim of: 
(1) screening, in particular high-throughput and combinatorial screening, (2) mimicking of natural microenvironment ranging from 3D hydrogel-based cellular niches to organ-on-chip devices; and (3) production of a new generation of deliverable materials.

\section{Screening cellular responses in microfluidic systems}

A growing interest in microfluidic systems is largely derived from their proven versatility in biosensor applications. This multidisciplinary research field rapidly delivered point-of-care diagnostic devices, which are predominantly based on transducer mechanisms using biomolecules for sensitive and selective recognition of analytes in the bioenvironmental or biological samples. Oligonucleotides, peptides, enzymes and other bioprobes, adsorbed on, covalently bonded to or otherwise connected with a transducer, enable quantification of very small amounts of biological (by)products, which are often difficult to detect. From the very first applications of microfluidic devices, used to quantify simple molecules in solutions, to a now mature field with sophisticated devices using immobilised biomolecules in surface transducers or suspended particles, a giant library of microfluidic biosensors has been developed, meeting the needs of applications at different levels [8-10].

A similar trend is observed in the development of microfluidic devices specifically designed for biomedical research that incorporate cells with different levels of organization, with the aim to study cellular responses to direct or indirect stimuli. In contrast to classical tissue culture systems, where cells are exposed to bulk materials or compounds in solution, microfluidic systems are useful to study a response or interaction in greater detail, such as cell attachment dynamics, material degradation in time, controlled release, etc. [11-13]. Owing to a great parallelization potential, microfluidic platforms are especially suitable for scaling-up of screens while keeping the cost low, as a consequence of the low volumes used. Such platforms can be developed by using the strengths of microfluidics such as the possibility to create gradients, or by applying smart, multi-layered, complex fluid networks that are specifically designed to assist assays with single cells, cell monolayers, or aggregated or encapsulated cells. Furthermore, coculture can be easily performed through compartmentalization, and combinatorial screens are possible whereby cells are simultaneously or subsequently exposed to two or more cues, of the same, or different nature.

Nevertheless, multiplexing variables in a single fluidic layer may be technically challenging when standard techniques, based on one-step soft lithography are used, since fluidic channels cannot cross or overlap. In such cases, other techniques, including 3D printing [14-16], sequential overlapping layers [17-19], porous or impermeable membranes [20-22] or valves [23] may help to increase multiplicity of variables with higher level of freedom in interconnectivity. Highly sophisticated operations and effective use of the hierarchical structuring of microfluidic compartments can also be achieved in centrifugal microfluidics [24].

\subsection{Multiplexing variables into arrays}

Different levels of complexity can be found in microfluidic devices used for screening mammalian cell behavior upon exposure to chemical or physical cues, ranging from single cells, via cell monolayers, aggregates, or organoids to complete organ mimics.

\subsubsection{Single cells}

The study of single cells as individual source of information has been predominantly enabled by geometrical and hydrodynamic docking possibilities within microfluidic systems
[25]. Furthermore, options of active cell trapping by means of chemical, electrical or optical signals have also been described [26]. Caging of cells can be used for precise delivery of nanoliter volumes of nutrients or chemicals in time [27], for control over cell-cell interactions [28] and subsequent analysis by constrained lysis or non-destructive assays.

In single-cell platforms, only few hundreds of cells are required, numbers that may be limiting when conventional analysis techniques are applied. Faley et al. [29] described a microfluidic technique by which rare chronic myeloid leukemia CD34+ hematopoietic stem/progenitor cells could be individually immobilized, followed through live imaging and assessed for protein post-translational modification, and rapidly fixed in situ (Fig. 1A). In line with this example, many biological assays in microfluidic devices are imaging-based, although dynamic micro flow cytometers have also been proposed [30]. Arrays of single-cells for screening of drugs can be particularly useful to track direct parameters such as stem cell division symmetry, proliferation rate and motility of cells, in addition to analysis of specific signaling pathways [31,32]. For example, Wlodkowic et al. [33] induced mitochondrial pathway for apoptosis by Staurosporine and monitored real-time cellular events through increase of propidium iodine permeability, apoptosis marker SYTO 62 and plasma membrane permeability marker SYTOX Green.

Besides immobilized single cell arrays, encapsulation of single cells into aqueous phase core droplets [34] was used to study clonal heterogeneity in a cell population [35] or for coding of compound libraries in high-throughput screenings [36].

\subsubsection{Cell monolayers}

Many conventional microfluidic systems, produced using soft lithography fabrication methods, are particularly suitable for studying cells in monolayer. Bio-analytical assays are performed in micrometer-scale culture reservoirs, using continuous or periodic perfusion regimes for media refreshment and reagent delivery. Commonly, designs of systems with multiple chambers allow parallel readouts from individualized cell populations, through independent experiments. For example, an integrated microfluidic array plate was proposed by Dimov et al. [37] where cytotoxicity, real-time nuclei acid sequence-based amplification and immunofluorescent protein expression detection were performed in parallel. Yang et al. [38] proposed a system creating a 3D hypoxic microenvironment that enabled efficient quantification of human neuronal stem cell self-renewal and differentiation alterations, as an alternative to 2D and 3D hydrogel-based macro culture systems. The authors used the system to evaluate the effect of extracellular matrix (ECM) protein on the expression of a number of neuronal markers.

Scalability towards higher throughput and integration are among the most important promises of microfluidic devices for studying cell behavior. Additionally, along with minimization of handling and destructive processing steps, efficient spatiotemporal use of liquids is of substantial benefit. An example of a system in which a number of these properties were integrated was given by Wang et al. [39], showing coordinated use of valves, and application of reporter plasmids encoding fluorescent proteins for fast and non-destructive live readouts on active biochemical pathways.

\subsubsection{Aggregates and spheroids}

While multicellular bodies such as aggregates or spheroid-like functional units can provide important information on cell-cell and cell-ECM interactions, platforms enabling their culture and analysis need to satisfy very specific requirements. As a result, available options to comprehensively study the physiology and pathophysiology of structures like islets of Langerhans, are limited. A successful example was given by Nourmohammadzadeh et al. [40], who, based 

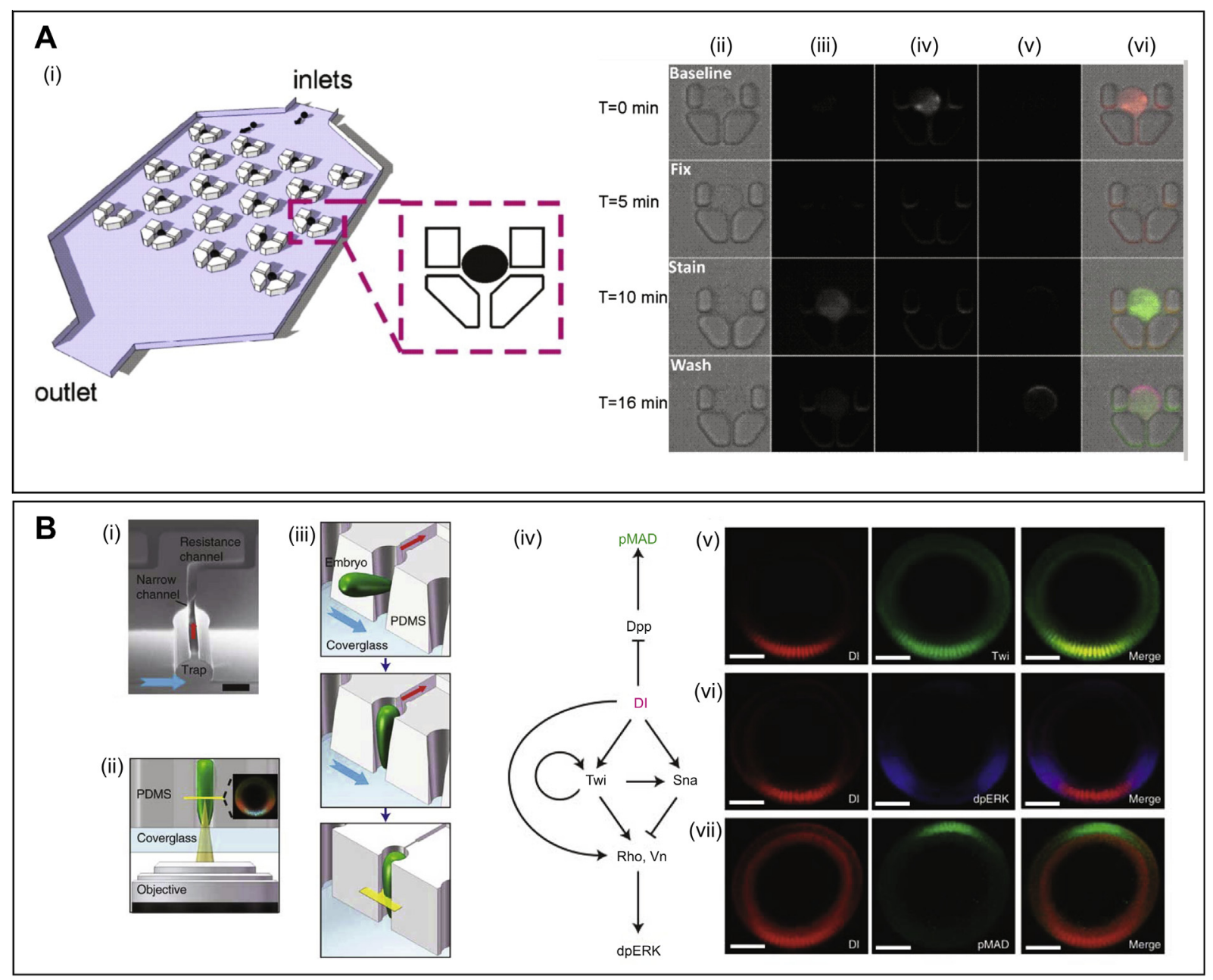

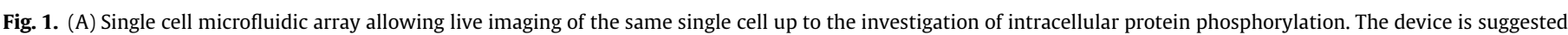

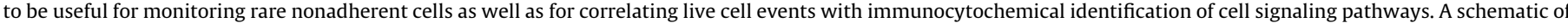

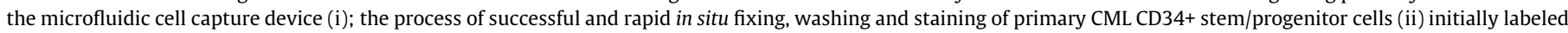

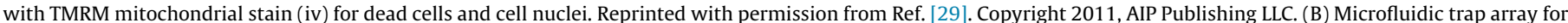

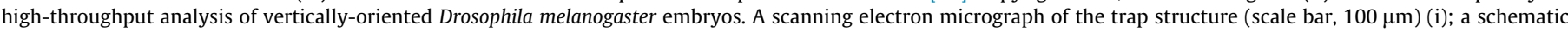

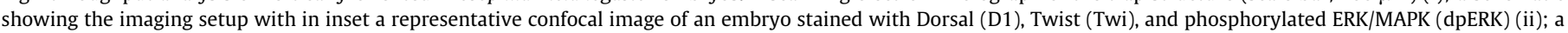

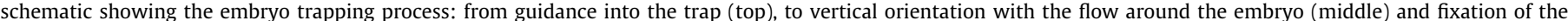

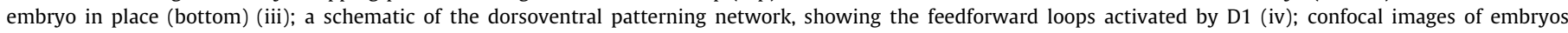

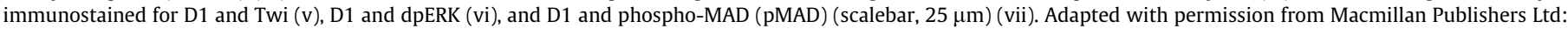
Nature Methods [43], copyright 2011.

on hydrodynamic trapping strategy coupled with islet microencapsulation in alginate microbeads demonstrated the hypoxia impairment of intracellular calcium signaling, and mitochondrial energetic and redox activity, with single islet resolution.

Microfluidic platforms have also been used in the study of embryoid bodies, three-dimensional aggregates of pluripotent stem cells, including their formation [41], development [42] and eventual harvesting. An example of how microfluidics can provide multi-dimensional control and delivery of asymmetric cues in the formation of complex tissue is given by Chung et al. [43]. This platform enabled study of polarization of embryoid bodies, through actuating gradients of morphogens and real-time reporting on pattern formation and development status (Fig. 1B.i-iii). More specifically, the study investigated dorsal-to-ventral patterning regulation (Fig. 1B.iv), a system dominated by feed forward loops. While polarization over Twist (Twi) and Bone Morphogenetic Protein (BMP) gradients confirmed the existing knowledge, the platform also enabled, for the first time, quantification of the
Mitogen Activated Protein Kinase (MAPK) phosphorylation gradient (Fig. 1B.v-vii).

\subsubsection{Organisms}

As a next step towards increasing complexity, microfluidic systems have also been applied in the study of complete organisms, usually small living eukaryotes, in real-time experiments within a time frame of minutes to hours. This type of experiments provides a more integrated view over the experimental setup, e.g., an overview of physiological events from uptake of a drug up to its effect. Drosophila melanogaster or Caenorhabditis elegans (C. elegans) are well-established model organisms, with rapid life-cycles and easily generated pools of individuals [44,45]. Such models are not only useful in developmental, genetic and disease studies, but they may also aid development of organ- and tissue regenerative strategies $[44,46]$.

Recently, Levario et al. [47] presented a microfluidic trap array to rapidly orient hundreds of Drosophila embryos. In 
developmental studies, gradients of diffusible molecules are often used to induce morphogen concentration-dependent patterns. The device enabled improved imaging and data acquisition of dorsal-ventral gene patterning during embryogenesis, based on the fact that, by default, the longer anterior-posterior axis is better suited for microscopy setups, given the ellipsoidal shape of the embryo. Carr et al. [48] used free living nematodes such as C. elegans and parasitic Oesophagotomum dentatum for screening drug resistance to anthelmintics in microfluidic devices. Given the molecular biology tools available for detecting an altered genotype due to this particular drug resistance, this microfluidic chip offered the advantage of running numerous experiments in parallel, and tracking changes real-time.

In other studies, whole organism microfluidic set-ups based on C. elegans addressed questions as diverse as the worm's lifespan (important in ageing studies) through longitudinal measurements by employing fluidic clamps [49] or difference between wildtype and drug-resistant types by recording sensitive electropharyngeograms [50]. Other model-organisms with strong interest in regeneration have also been successfully used in microfluidic approaches, such as the vertebrate zebrafish (Danio rerio) [51], or the pluripotent cell rich planarians [52].

\subsection{Gradients for screening}

One distinct capability of microfluidics is the well-controlled generation of gradients of species in solution. Gradients of molecules can be generated in two ways, namely advection, being the mass transport by the fluids bulk motion (flow-based gradient generation), or by diffusion, being the spreading of unequally distributed molecules by biased random walk induced by Brownian motion (diffusion-based gradient generation). Two excellent reviews have been published on the topic of gradient generation by microfluidics. While Kim et al. [53] focused on technological advancements in microfluidic gradient generators, dividing them into flow-based and diffusion-based platforms, Berthier et al. [54] discussed key applications of microfluidic gradients for biological applications and elaborated on their future perspectives.

In microfluidics, as well as in materials science, gradients are often described as a good technical resource of multiple conditions within a relatively small area/volume. Importantly, while a gradient, by definition, should refer to a linear, or at least a continuous progression of a variable, this term is frequently also used to describe a step-wise progression, commonly referred to as discrete gradient [55].

\subsubsection{Soluble gradients}

The ability to create gradients is particularly useful for studying toxicity, cell migration or phenotype changes, upon exposure to a compound in the solution. Spatiotemporal information of high resolution is thereby an important advantage. Several devices have been proposed to study the effect of soluble species in cell culture media delivered gradient-wise including assays for bacterial or mammalian cell chemotaxis [56-58], cytotoxicity [59,60], transcription factor translocations [61] and differentiation [62]. This kind of platforms may enhance the power of assays as compared to conventional experimental set-ups by significantly decreasing the number of cells needed for robust and statistically relevant readout. As an example of the use of microfluidics to create tightly controlled gradients, Zhang et al. [63] presented a high-throughput microfluidic platform designed to understand cancer metastasis by monitoring epithelial-mesenchymal transition, which is a core molecular program that enhances cell migration. In this set-up, resistance of cells to antimetastatic drug gradients created through microchannels was studied, either in their epithelial state or after mesenchymal transition induced by a plasmid vector (Fig. 2A).
Gopalakrishnan et al. [64] developed a real-time screening platform for studying infection and immunological response through tracking of cell migration. In this design, a chemokine gradient was created, propagating from a source, and representing therewith infectious foci (Mycobacterium avium), to study migration of adherent macrophages, non-adherent T-cell hybridomas and dendritic cells. The system provided a decision-making monitoring assay as a valuable tool for studying cellular migration and selforganization. The authors asserted on the relevance of such a platform as a non-animal alternative to address complex multicellular biological processes as diverse as metastasis, immunotherapy, or tissue remodeling.

Dynamic microfluidics-based cell culture chambers have been developed to study response of single cells within a monolayer, upon exposure to soluble cues, often using image-based cytometric analyzes. In such systems, species in solution are delivered through perfusive or diffusive fluidic regimes. Perfusion derived gradients are generally generated by an array of hierarchically ramified microchannels, upstream of the culture chamber $[65,66]$. A hydrodynamic junction can be used for diffusive mix, creating a progressive gradient over the length of the resulting channel $[60,66]$. Diffusion-based gradients are a result of a source-sink arrangement siding the chamber, whereby a directional movement by diffusion is observed from the compartment containing higher concentration to the one with lower concentration $[61,67]$. Image-based cytometry, which is frequently used for high-content assessment of cell responses in such devices, often employs fluorescent assays combined with automated microscopy image acquisition. For example, Harink et al. [61] developed an end-point assay to quantify translocation of hypoxia-inducible factor 1 alpha in cells exposed to a diffusion-generated gradient in a closed, glass microfluidic system. A translocation assay was also used by Awwad et al. [65] in a long perfused cell culture chamber where Chinese Hamster Ovary cells ( $\mathrm{CHO}$ ), hosting a reporter plasmid with a fluorescent fusion protein human NF- $\mathrm{kp} 65$ and pHyg, were actuated by interleukin $1 \beta$ gradients, demonstrating a linear response in the concentration range of $0.005-0.1 \mathrm{ng} / \mathrm{ml}$ (Fig. 2B).

In contrast to the previous examples in which continuous gradients were created within the cell culture chamber, systems containing multiple parallel compartments can alternatively benefit from a discrete concentration gradient generator, derived from hierarchically ramified fluidics, enabling fast serial dilutions to non-connected sided compartments. This type of approach has been used, for example, in cell cycle analysis [68] and cytotoxic drug screening [69].

\subsubsection{Surface-bound gradients}

Besides application of microfluidics to generate gradients of soluble species, several systems have been proposed to create surface-bound gradients, which is particularly interesting for the field of biomaterials. For example, various attempts have been undertaken to mimic the microenvironment of the ECM and its proteins, which are known for their role in developmental patterning, to stem cell niche support and regulation of the progression of cancer and genetic diseases [70]. Various families of biomolecules, including peptides, proteins, polymer brushes, electrolytes and ECM-like polymers have been successfully applied on surfaces of biomaterials in a gradient-wise manner. As suggested by $\mathrm{Wu}$ et al. [71], different techniques to achieve such surface modification can be categorized into top-down and bottom-up approaches. The first group comprises techniques such as plasma modification by selective etching of surfaces, electrical discharge, ultra-violet irradiation and chemical degradation, whereas in the second group techniques such as infusion (frequently used as dip-coating), diffusion, micro contact printing, microfluidic lithography and electrochemistry can be found. 

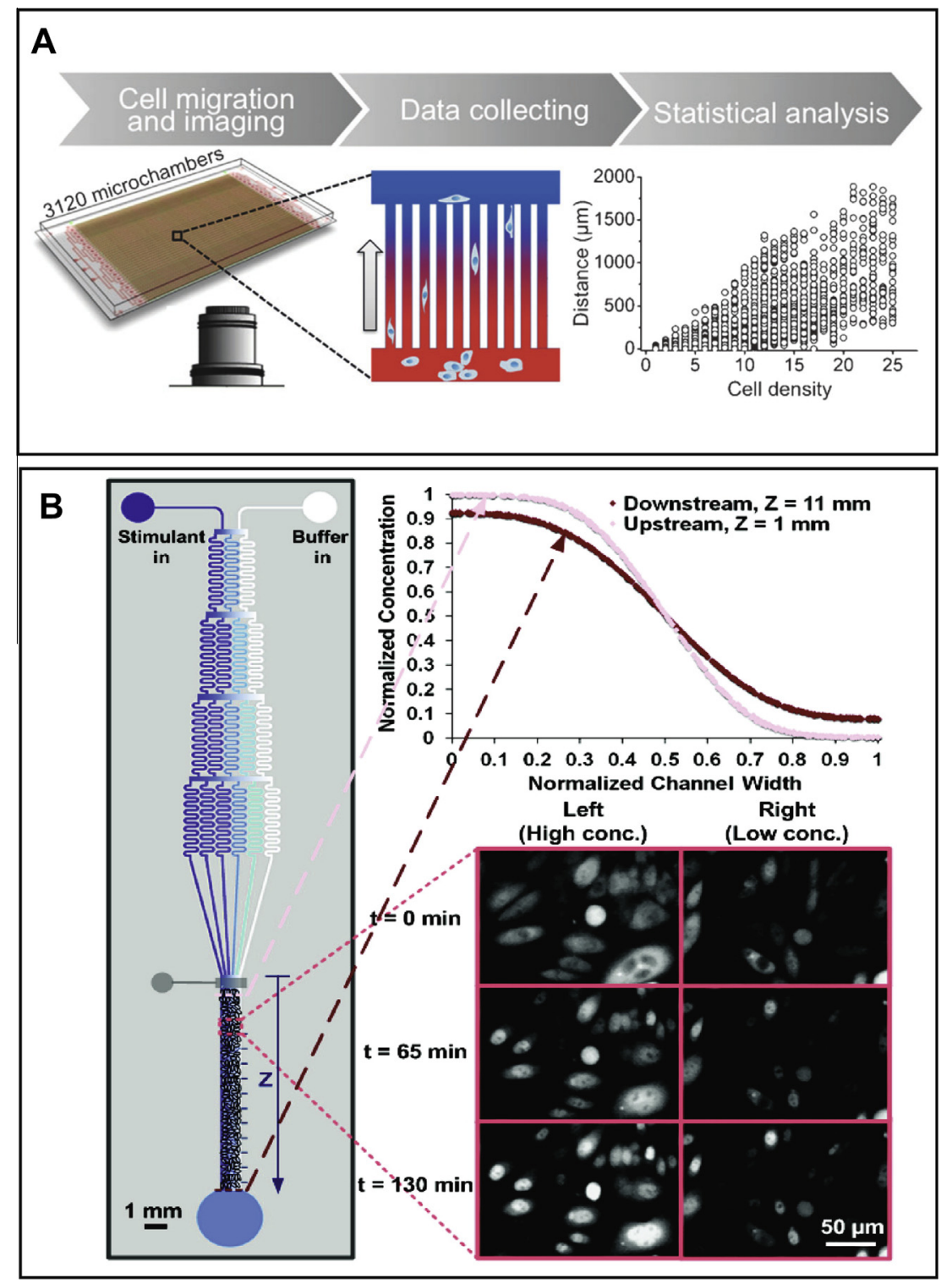

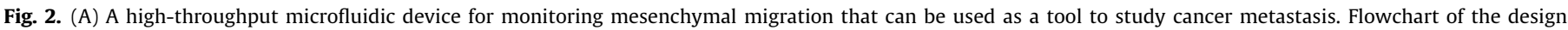

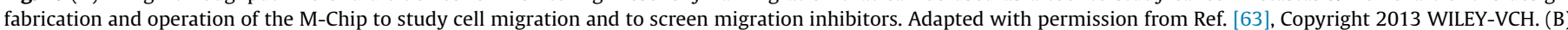

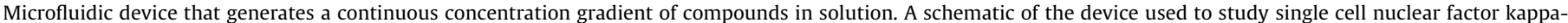

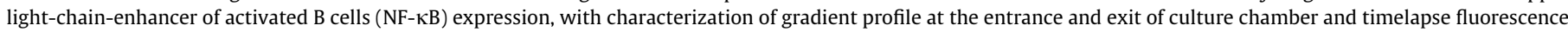

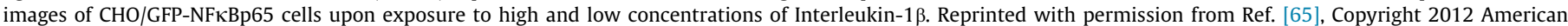
Chemical Society.

Microfluidic systems have been useful not only for controlled biochemical functionalization of biomaterial surfaces, but also for generating materials with spatially controlled physical properties, such as stiffness, porosity, charge, roughness, etc. For example, with the aim to mimic the natural ECM, Almodovar et al. [72] deposited polymeric polyelectrolyte multilayer (PEM) films, characterized by an anisotropic composition of topology gradients (microbeads), biochemically decorated with cell adhesion molecules (poly-(L)-lysine)-FITC, RGD) and stiffness gradients spanning linearly over centimeters length (Fig. 3A). These gradients were created by employing a sacrificial microfluidic device, and it was shown that they could be used to control adhesion and spreading of $\mathrm{C} 2 \mathrm{C} 12$ myoblasts over the length of the gradient.

Many different techniques have been proposed for the patterning of surfaces by employing microfluidics, taking advantage of laminar flow and intrinsic diffusive regimes of solutions and dilute species. Didar and Tabrizian [73] presented a system allowing combinatorial delivery of soluble gradients over pre-activated surfaces, in which the molecule of choice could covalently attach to the surface in a controlled manner, by controlling the perfused solutions mixture. As a proof of concept, 2D gradients of ArgGlu-Asp-Val (REDV) and KRSR (Lysine-Arginine-Serine-Arginine) peptides were distributed and immobilised along the length and width of each channel, remaining functional under high shear stresses ( $50 \mathrm{dyn} / \mathrm{cm}^{2}$ ), and subsequently validated for adhesion of primary human umbilical vein endothelial cell (HUVEC).

Also surfaces of hydrogels, highly hydrated biomaterials, with relevance in biomedical applications such as articular cartilage, osteochondral and bone repair [74], can be successfully patterned by means of microfluidics. For example, hydrodynamic flow focusing has been successfully used for selective exposure and uptake of tagged proteins into gels in a gradient fashion, as reported by 

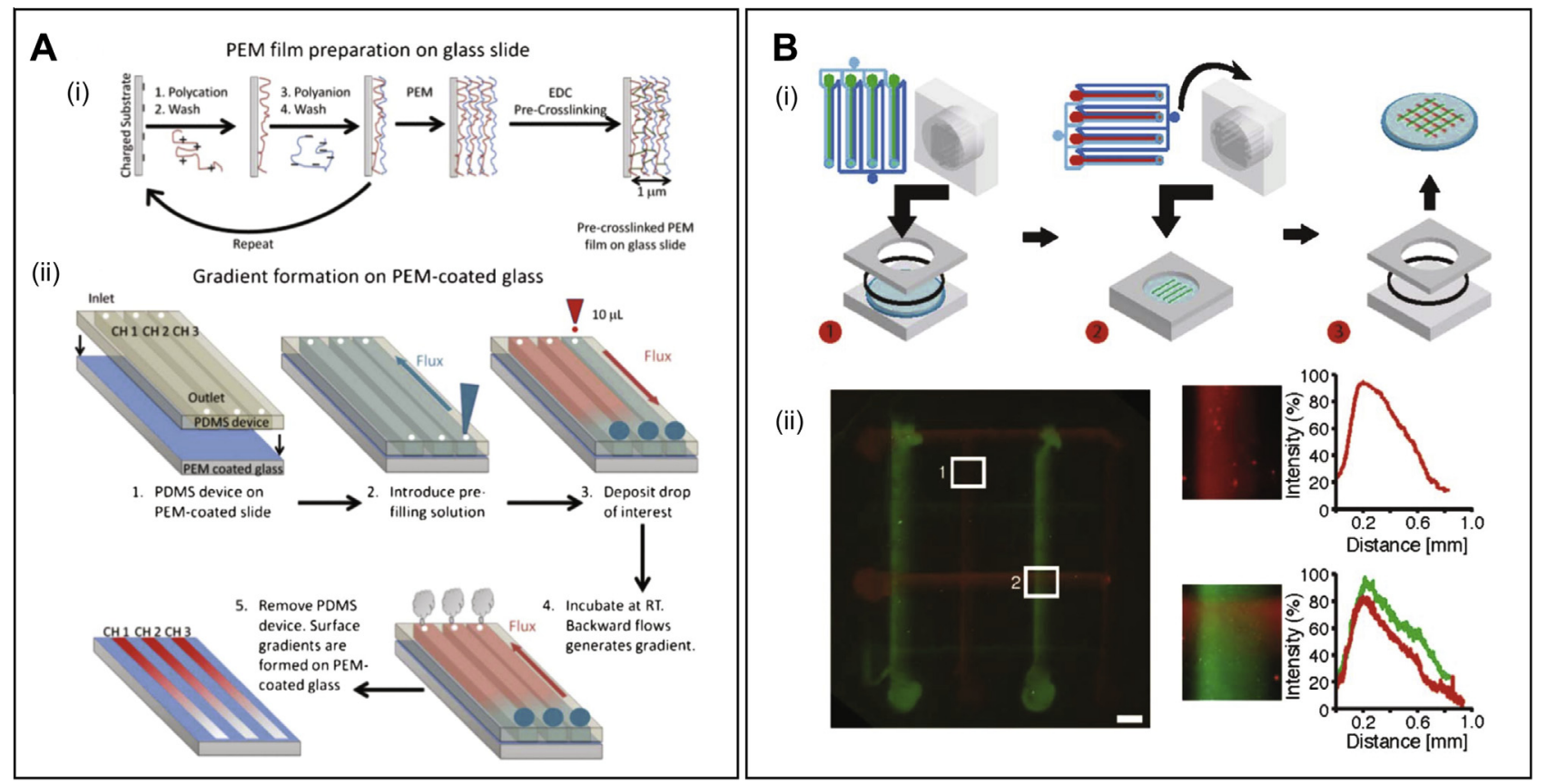

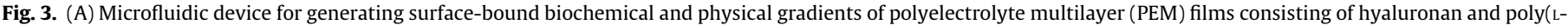

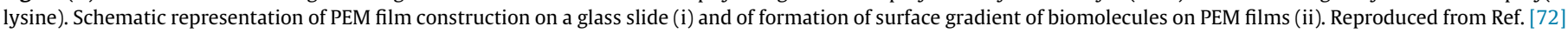

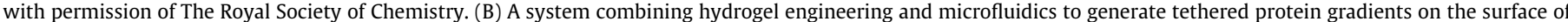

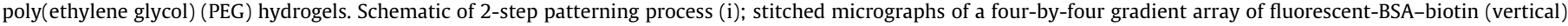

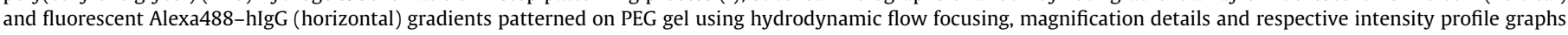
(scale bar $=900 \mu \mathrm{m}$ ). Adapted from Ref. [75] with permission of The Royal Society of Chemistry.
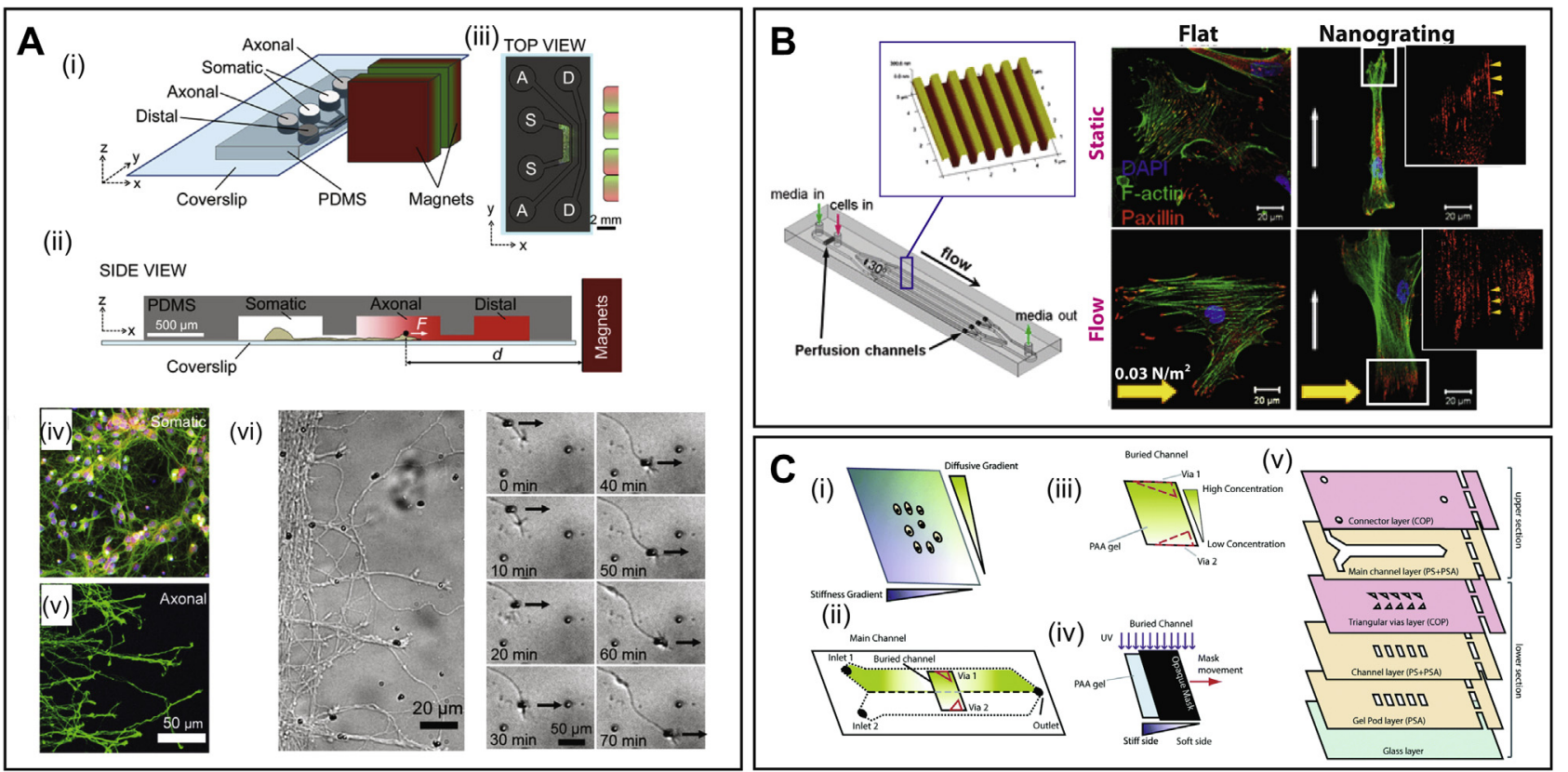

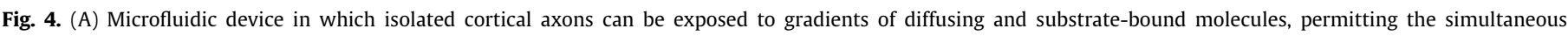

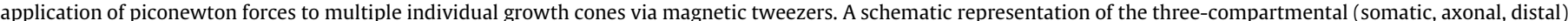

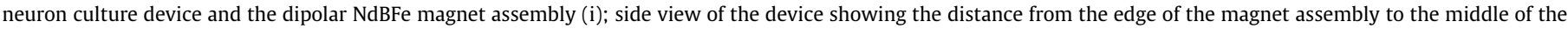

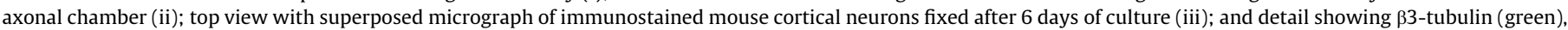

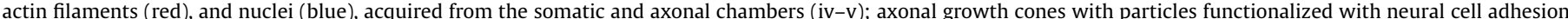

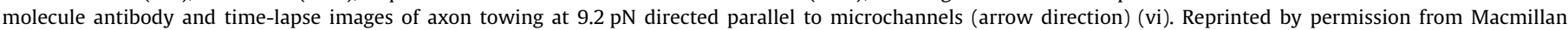

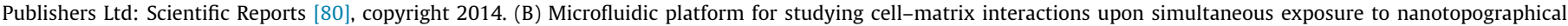

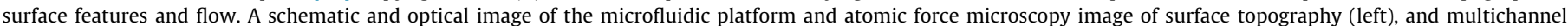

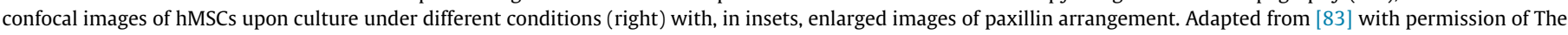

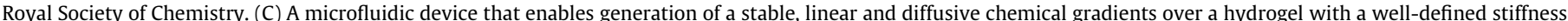

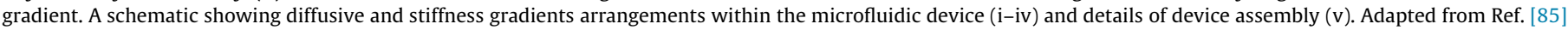

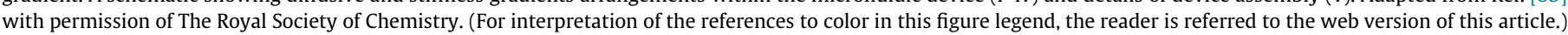


Cosson et al. [75]. In this work, poly(ethylene glycol) (PEG) hydrogels containing PEG-tethered NeutrAvidin/ProteinA could be on-demand patterned by various gradient profiles of biomolecules, including the formation of surface-bound overlapping gradients. Proof-of-concept was provided by immobilization of leukemia inhibitory factor (LIF) on PEG-ProteinA films, successfully sustaining colony formation of embryonic stem cells while retaining their pluripotency (Fig. 3B).

\subsection{Combinatorial screening}

As mentioned before, a particularly important advantage of microfluidics-based systems above other screening systems is their integration capability, allowing multiplexing of variables of the same or different nature within a single platform. Ranging from relatively simple combinatorial mixing to more sophisticated multivariable devices [76-78], such systems enabled analyzes that would otherwise not be possible. Examples include systems to study cross effects of fluidic shear stress and mechanical displacement [79], exposure to chemical gradients and electromagnetic stimulation [80], surface-bound and compounds in solution [72], among many others. For example, Li et al. [81] presented a dual system in which chemical gradients and electrical fields co-exist, using it to gain fundamental knowledge on the effects of competing chemoattractant gradients and direct current electric fields on cell migration. Such a system may aid development of novel therapeutic strategies for cell trafficking-mediated diseases, or for understanding physiological processes common in autoimmune diseases, cancer, and wound healing, where electrical components are used to remotely orient cellular processes in tissues.

In an attempt to find optimal culture microenvironment for CHO-K1 cells in a perfused culture chamber, Hattori et al. [82] developed a microfluidic platform in which combined effects of ECM proteins collagen, fibronectin and laminin, that were used as a substrate, and soluble medium factors were studied.

Kilinc et al. [80] described a microfluidic device in which isolated cortical axons were exposed to both diffusive gradients and substrate-bound chondroitin sulfate proteoglycans (CSPG). Superparamagnetic microbeads, functionalized with an antibody against neural CAM, targeting axonal growth cones, under simultaneous application of piconewton $(\mathrm{pN})$ forces by magnetic tweezers, were shown to drive elongation of individual growth cones. Interestingly, parallel towing of axons towards inhibitory environments, representative of the glial scar, where regenerating axons face repellent surfaces, suggested that mechanochemical stimulation coupled with directed inhibition of motor proteins and ROCK pathway may be a promising therapeutic approach for the repair of the damaged central nervous system (Fig. 4A). Also addressing cell growth and adhesion, Yang et al. [83] demonstrated that orientation and deformation of cell cytoskeleton and nuclei in human mesenchymal stem cells (hMSCs) could be regulated through the interplay of both nanotopography and fluid shear stress (Fig. 4B).

Other examples of integrated platforms that take benefit from engineered gradient profiles are the ones designed to study oxygen tension effects, for example as a means to assess cellular responses to hypoxic conditions. Wang et al. [84] integrated oxygen and chemical concentration gradients in a single device to assess the efficiency of antitumor drugs tirapazamine and bleomycin on human lung adenocarcinoma A549 cells and human cervical carcinoma HeLa cells. The authors demonstrated a dose-dependent viability decrease induced by the drugs, and a hypoxia-induced cytotoxicity of tirapazamine.

In the study by Garcia et al. [85] a hydrogel substrate with stiffness varying in a gradient-wise manner, which was achieved using a sliding-mask photopolymerization process, was combined with a fluidic assembly that enabled generation of overlapping gradients of hepatocyte growth factor in a solution, over the substrate. Combined effects of substrate stiffness and growth factor concentrations at different values were studied by looking at epithelial scattering of MDCK cells, elegantly demonstrating the power of gradients for screening (Fig. 4C).

In addition to systems exploring simultaneous effects of variables of different nature, control over fluidic regimes also allows for combinatorial screening of two or more compounds in the solution. Simple injection of concurrent flows can be used to create complex matrices of concentrations, useful in dose-response drug screening of two components. Kim et al. [86], for example, described a programmable microfluidic cell array in which gradients of concentrations and 64 pair-wise combinations could be created on-chip. This device was used to screen and optimize chemotherapeutic treatment against PC3 prostate cancer cells.

\section{Biomimetic microenvironments}

Besides the so far highlighted possibilities of microfluidic technology to increase throughput of screening through parallelization and integration, expectations are at least as high when it comes to creating microenvironments that closely resemble the natural systems. Through compartmentalization in 3D, resulting from various multilayering options, initially developed within the microelectromechanical system (MEMS) field, complex microenvironments can now be created relatively easily at low cost. Systems allowing multi-layered cell (co)-culture, with spatiotemporal control over nutrient- and soluble cues, and simultaneous incorporation of physical cues can now be realized [87]. These technological developments, however, are only useful when supported by fundamental understanding of the natural systems. Indeed, in vitro platforms are always a mimic of the natural system, regardless of their complexity. It is therefore important to make the right choice of the function to be mimicked, as justification of this choice will eventually determine whether a system is considered valuable (i.e. truly predictive of the in vivo situation) or not.

\subsection{Application of $3 D$ matrices}

As mentioned earlier, hydrogels are remarkably useful as delivery vehicles for factors of interest, as well as facilitators of cell growth and ECM production. This application versatility, combined with relative ease of handling through microfluidic channels justifies the widespread use of hydrogels to realistically recreate "artificial niches" in microfluidic systems, either in the form of 3D microfabricated compartments, or in droplets.

Various types of hydrogels have been processed in microfluidic systems [88], with collagen [89-92], PEG [1,93,94], agarose [95], fibrin [92,96], and PEGDA $[97,98]$ being most commonly used as single compounds or in mixtures.

Hydrogels also allow 3D entrapment of molecules, for example in a gradient fashion that would otherwise be added to bulk solution. As summarized by Malda et al. [99], different strategies are available for hydrogel gelation, allowing shaping of structures either by physical (ionic, stereocomplex, thermal) or chemical (UV, wet-chemical) crosslinking methods. Structured, patterned or gradient-wise decorated hydrogels, of particular interest in combination with microfluidics, are predominantly obtained by using photo-polymerization $[98,85]$ or thermal crosslinking $[13,93,96]$.

For example, Ostrovidov et al. [97] described controlled injection of the PEGDA hydrogel precursors into the microfluidic device from independent inlets and demonstrated formation of a gradient by means of incorporation of a fluorescent model molecule. Upon creation of a stable gradient, photopolymerization was used to 

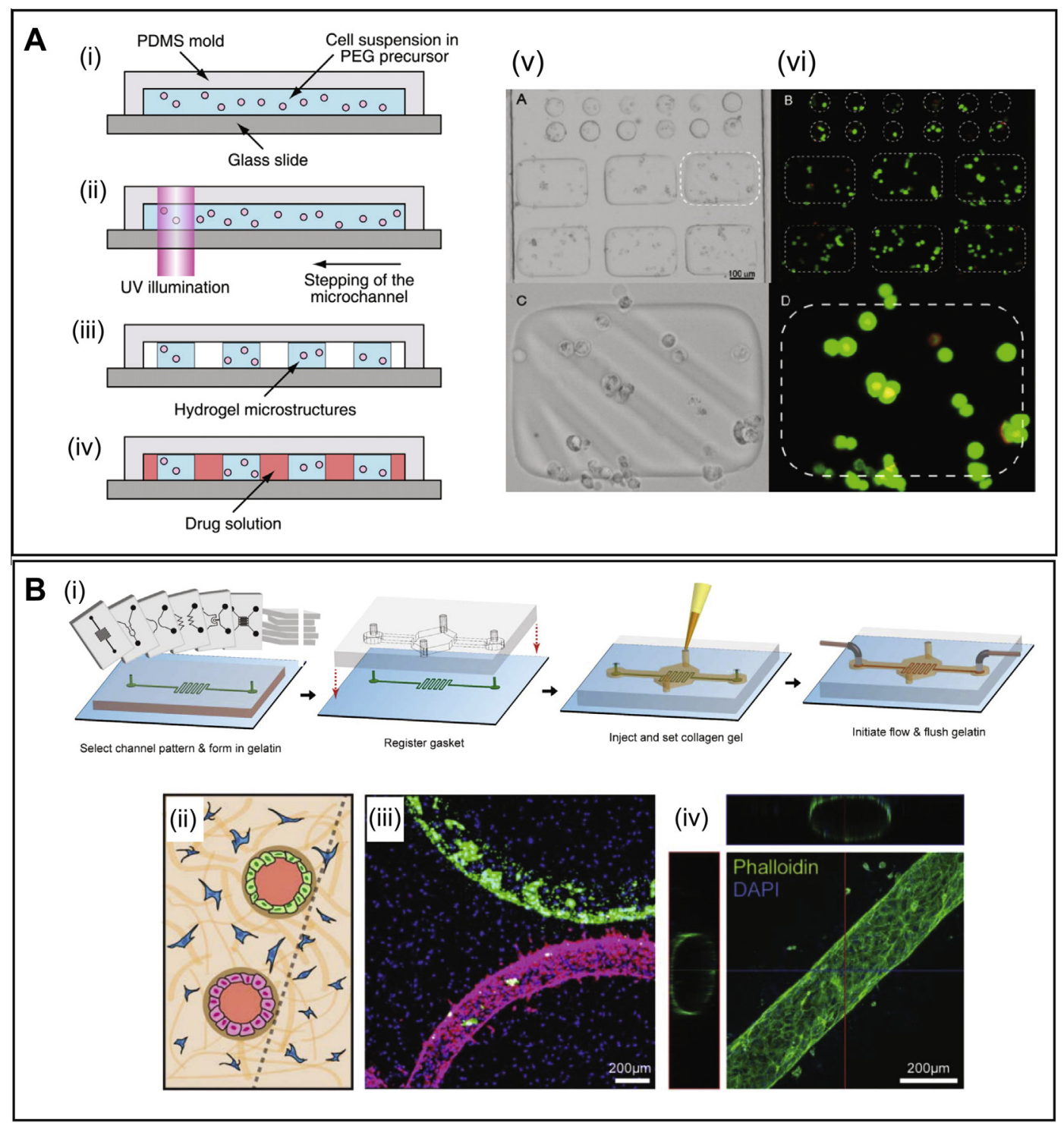

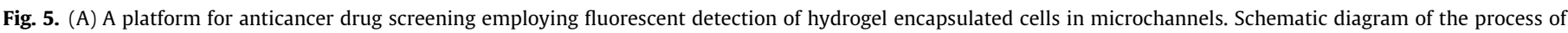

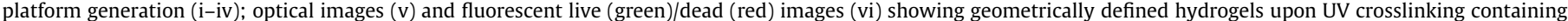

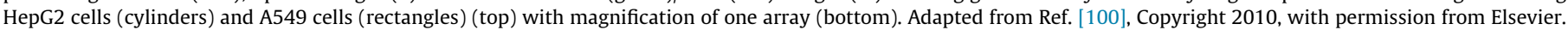

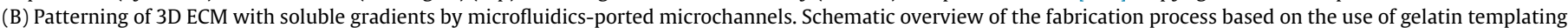

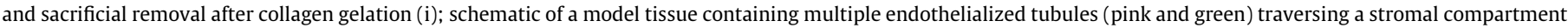

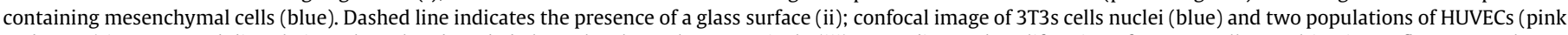

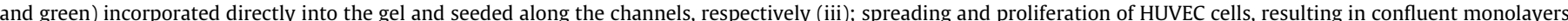

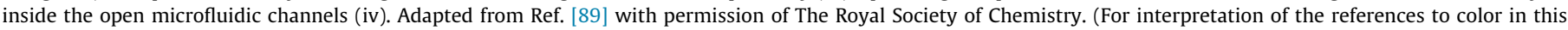
figure legend, the reader is referred to the web version of this article.)

fix the volume of interest, followed by the characterization of its release profiles and the study of the toxic effect upon loading with okadaic acid. Similarly, Gao et al. [100] employed photolithography to geometrically encapsulate human heptanoma HepG2 and human lung epithelial A549 cells in a PEG hydrogel inside a microfluidic device that was used to study apoptosis upon exposure to anticancer drugs (Fig. 5A).

While hydrogels are mainly used as 3D cell culture substrates and biomolecule carriers integrated into a microfluidic system, a number of studies exists in which hydrogels were used for defining the microfluidic structure. This was, for example, well-illustrated by Baker et al. [89], who used an ECM gel precursor solution and casted it over a sacrificial gelatin mold to create the fluidic compartments, followed by gelation and dissolution of the gelatin. The 3D ECM microfluidic device proved to be perfused, leakage- free, and able to accommodate cell culture. Moreover, the matrix easily enabled diffusive gradients from the channels through the mesh as well as co-culture, with fibroblasts embedded in the matrix and HUVECs in the channels, mimicking the vascular endothelium (Fig. 5B).

\subsection{Compartmentalization and networking}

Compartmentalization is a key factor in the use of engineered microfluidic systems aiming at mimicking complex, organ-like microenvironments. From spatially segmented contiguous cell culture chambers, to complex tri-dimensionally ordered compartments, the number of possible designs is endless. The new advent of organ-on-chip has initiated important discussions regarding relevance of such systems in terms of resemblance of 

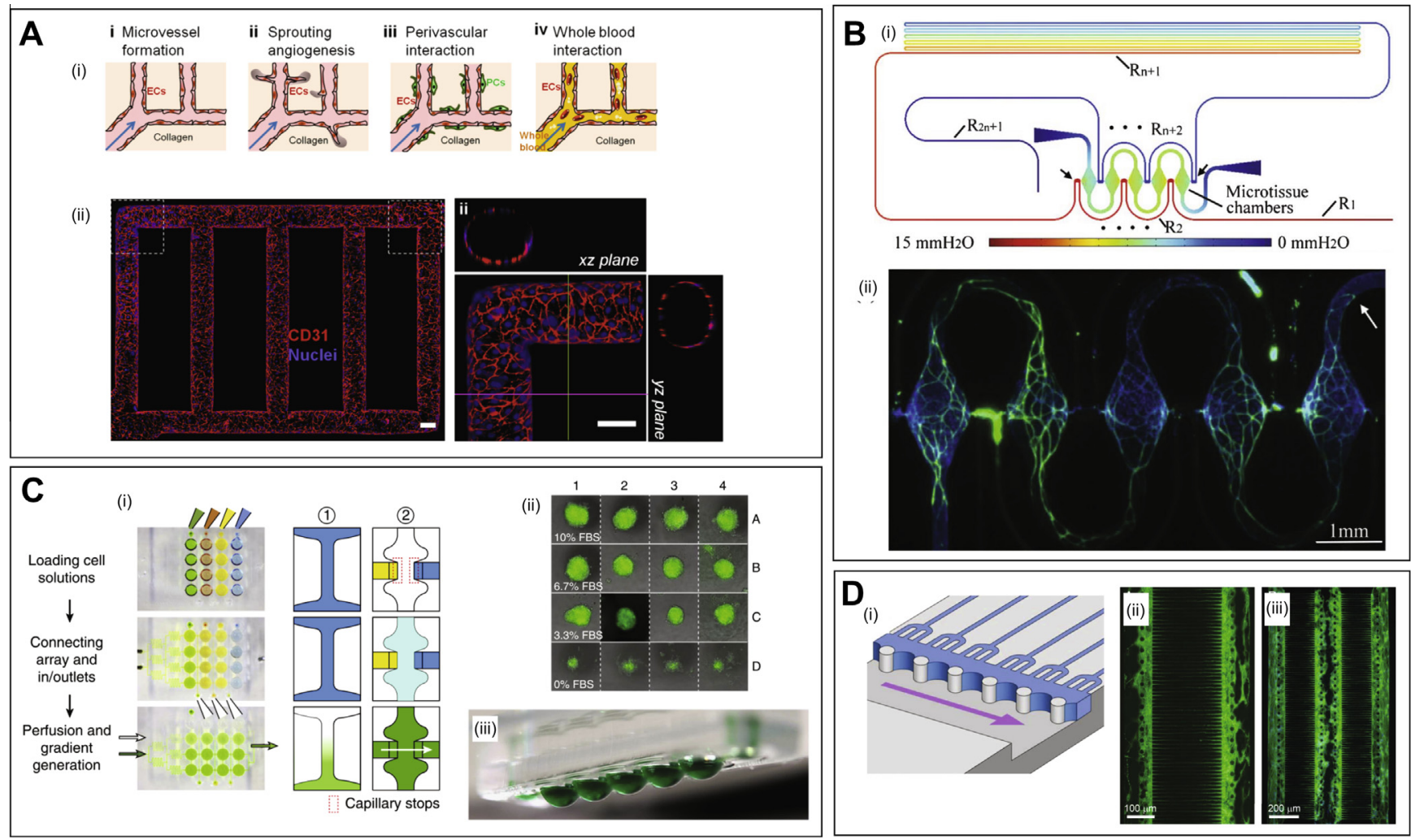

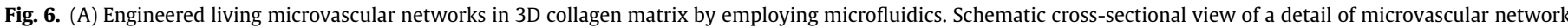

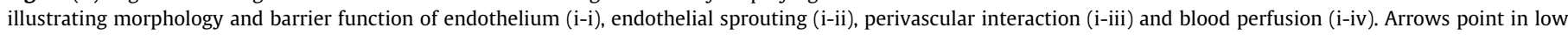

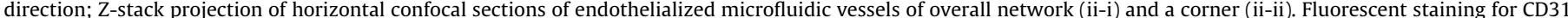

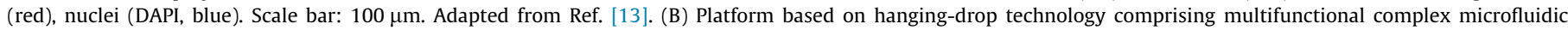

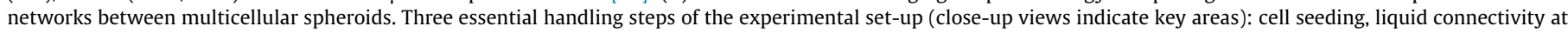

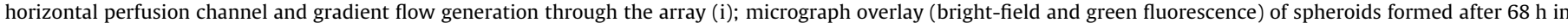

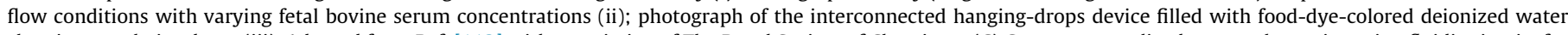

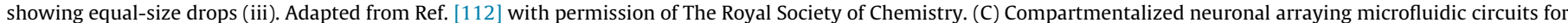

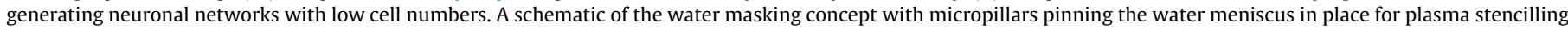

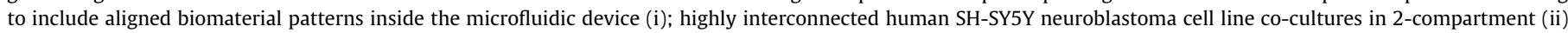

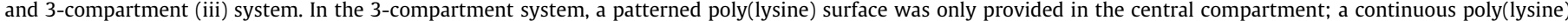

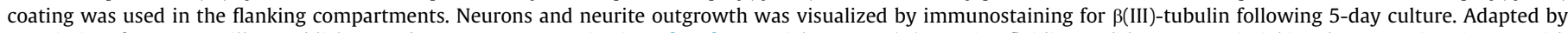

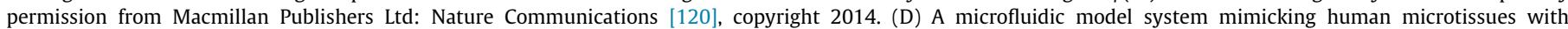

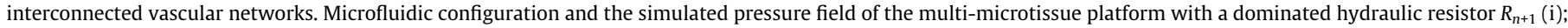

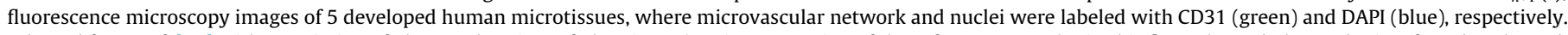

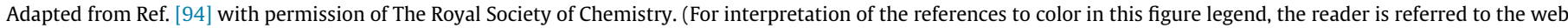
version of this article.)

natural microenvironment and thus predictability of their results for the in vivo situation, which, eventually, could significantly change the way research is done in many biomedical fields, ranging from drug screening to regenerative medicine, as recently reviewed in detail $[101,102]$. It is important to note that such systems are developed to mimic one or more functions of an organ or tissue rather than total physiology, as is demonstrated by systems representing functions of cardiac, neuronal or hepatic tissue below.

In 2010, Carrion et al. [96] described a recreation of the perivascular niche ex vivo in a 3D microfluidic device using endothelial cells, suspended in 2D fibrin patterned gels. In this work, the formation of a primitive vascular plexus and its maturation into a multi-layered (EC-, MSC-, and fibroblast containing) capillary network with well-defined hollow lumens was observed, in response to a compartmental segmentation in the access to nutrients. Focusing on angiogenesis and thrombosis, Zheng et al. [13] proposed an in vitro microvascular networks in 3D collagen scaffolds and demonstrated the nonthrombotic nature of the vascular endothelium, as opposed to a prothrombotic state upon induced inflammatory response (Fig. 6A). Similarly, in several other studies, vascular tissue was used as a model to develop a microfluidic setup, which was then used to study frequently occurring pathologies, such as microvascular thrombosis [13,103,104], as well as angiogenesis [105-108] or the blood-brain barrier [109-111]. Compartments were also successfully used to mimic more physiological conditions related to human vasculature. Hsu et al. [112] built a multimicrotissue array, allowing long term co-culture of endothelial and stromal cells, in presence of fibrin gel. By connecting each microtissue chamber on the top and bottom edges through a long interconnecting channel, a series of pressure dividers was created, comparable to an electric circuit. By adjusting the length of the channel, the magnitude of the pressure drop was adjusted. Each chamber containing microtissue within the platform was used as an independent experiment allowing quantification of the total vessel length per condition tested (Fig. 6B). With vascularization being a highly important player in the progression of many diseases as well as in regenerative processes, several other studies have employed microfluidic techniques to build 3D vascularized tissue, as reviewed by Hasan et al. [113].

Spatial segmentation using microfluidics can also be used to support individualized culture of aggregates and spheroids, of either non-adherent cell types or on repellent substrates that 


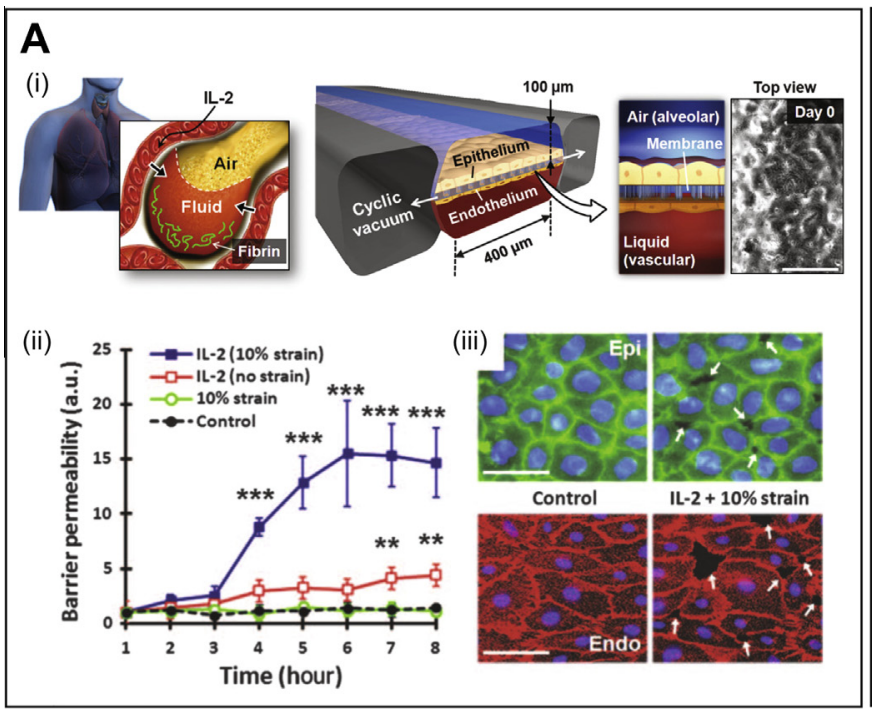

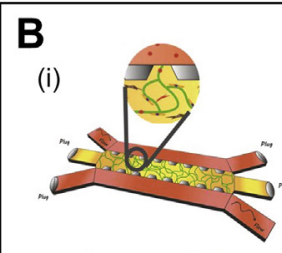

(iii)
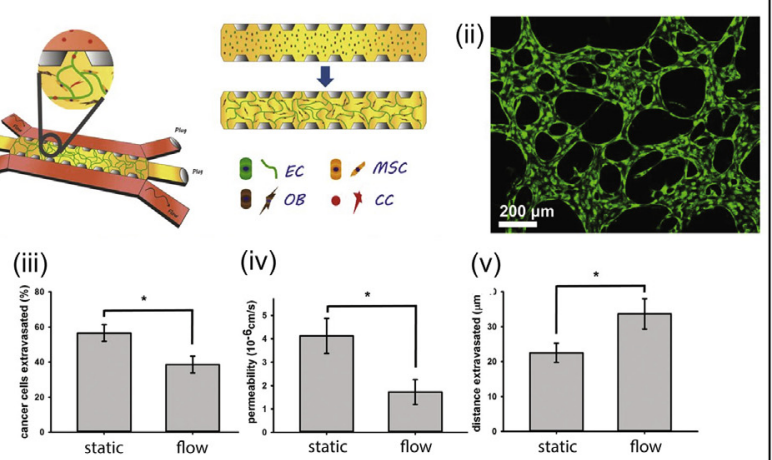

(iv)

(v)
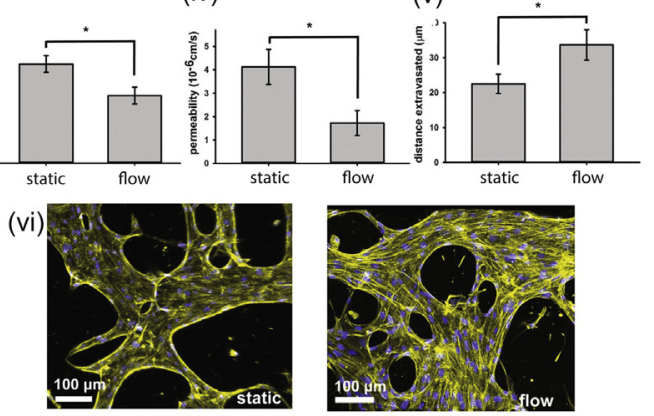

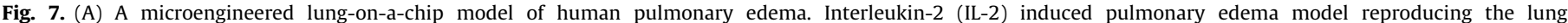

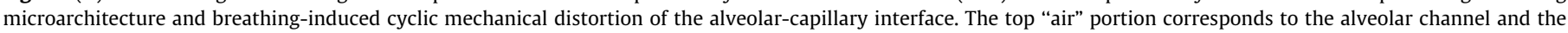

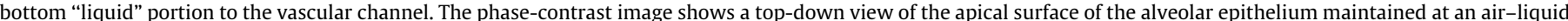

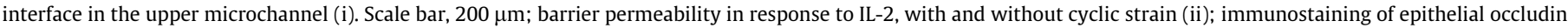

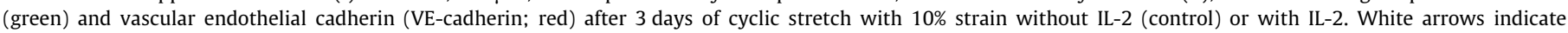

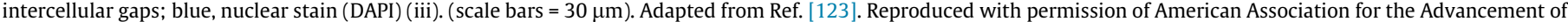

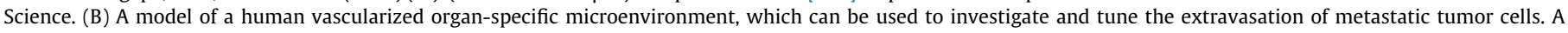

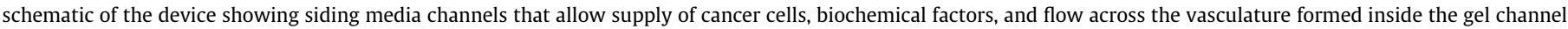

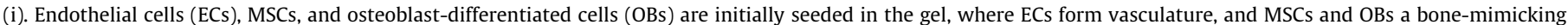

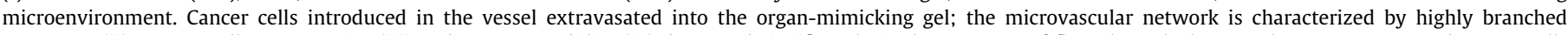

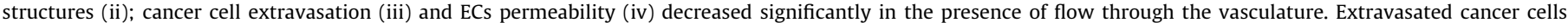

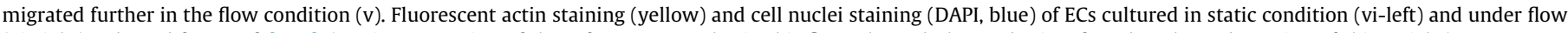
(vi-right). Adapted from Ref. [125]. (For interpretation of the references to color in this figure legend, the reader is referred to the web version of this article.)

induce aggregation. It is well-accepted that 3D cultures more closely mimic natural microenvironments of, for example, tumor tissues, thus improving reliability and predictability of studies evaluating efficacy of therapeutic intervention [114-117]. Given the versatility of microfluidics, and various levels of integration, cell culture and drug screening can in many cases be performed in a single platform $[118,119]$. For example, Frey et al. [120] developed a hanging-drop platform into which cells can be directly pipetted. The complex fluidic network can perfuse through the hanging drops, delivering nutrients, and other compounds of interest (Fig. 6C). Depending on the cell dispensing and perfusion configuration, exposure to soluble gradients and parallel or closed loop assays can be created. This system enables screening of the effect of compounds and delivers information on communication between individual segments of the platform as demonstrated by a sequential culture of hepatocytes upstream of human colorectal carcinoma cells HCT-116.

This feature of networking among compartments has probably been most extensively explored in the field of neurobiology, where such systems are becoming increasingly recognized as standard experimental tools. For instance, they have been used for long term co-cultures of hippocampal neurons and glia cells [121], or for patterning of geometrically defined networks for the analysis of neurodegenerative processes [122].

Based on the rationale that the brain is intrinsically complex, highly compartmentalized, layered, and contains multiple cell lineages with plastic connectivity via axon and dendrite outgrowths, Dinh et al. [94] developed a microfluidic circuit for single neuron arraying, combining a novel patterning technique based on plasma stencilling with water masking. The process allowed in situ and aligned biomaterial patterning for directional outgrowth in which inter-compartment neuronal networks are precisely defined (Fig. 6D).

\subsection{Functional organ-like models}

While previously described models in general mimicked a single, relevant function of an organ or tissue, recent developments have focused on biomimicking microfluidic assemblies with increased hierarchical complexity, actively actuated by external cues, alongside with dynamic mass transfer inputs, which can eventually produce quasi-real functional organ or tissue structures.

Probably one of the most illustrative examples of organ-onchips systems is the lung-on-chip device by Huh et al. [123,124], developed with the aim to establish a human disease model of pulmonary edema induced by drug toxicity. In this co-culture system, the alveolar-capillary interface of the human lung was reproduced by a multi-compartment device, with endothelial and epithelial cells forming a monolayer on either side of a porous stretchable membrane, that was actuated by air, like in a lung (Fig. 7A). The system demonstrated that mechanical breathing is critical in IL2-induced edema, that both epithelial and endothelial gaps contribute to pulmonary vascular leakage and that response to IL-2 does not require circulating immune cells. Additionally, the model helped to identify promising new therapeutic candidates.

Recently, Jeon et al. [125] reported on the development of a new 3D microfluidic in vitro model, based on a microvascular network, for characterization of organ-specific human breast cancer metastasis into bone and muscle. The authors identified the protective and anti-metastatic role of skeletal muscle cells and proposed the use of this platform for tailored screening of anticancer therapies in the context of personalized medicine (Fig. 7B).

Another interesting example was given by Sciancalepore et al. [126], who developed a bio-inspired renal microdevice aiming to simulate physiological conditions of a kidney proximal tubule. The authors developed a tubule that was populated by adult renal stem/progenitor cells (ARPCs) and supported by a perfused porous 
polycarbonate membrane. When confluent, the ARPCs were exposed to fluidic shear stress in the apical region, resulting in a polarized expression of aquaporin-2 transporter and to a $\mathrm{Na}^{+} \mathrm{K}$ ATPase pump located in the basolateral region. Notably, after only four days of culture, during which a confluent cell layer was formed, significant levels of urea and creatine could be recovered.

Another important promise of organ-like models is the ability to mimic the systemic effects, e.g., the effects of immune system on the progression of a disease or on the efficacy of a treatment. Furthermore, organ-like compartments may be organized sequentially to expose molecules to metabolic functions, in order to better predict their efficacy when administered systemically. In a recent review, Polini et al. [127] highlighted the developments in integration of multiple individual organ units into a single platform. In another review, Huh et al. [128] suggested that such integrated models may be useful for in vitro monitoring of different routes of drug administration (oral, aerosol and transdermal) and their effect on drug stability. While the majority of the so far developed organ-on-chip models have focused on study of disease progression and associated treatments methods, we recently discussed the potential of such models to study processes of tissue and organ-regeneration [129], and emphasized that complexity of such model may present new, different technological challenges.

\section{Biomaterial production using microfluidics}

As is described thus far, screening of biological phenomena and generation of physiologically relevant biological models are by far the most important applications of microfluidic systems in biomedical science. Nevertheless, such systems can also be very useful as tools for fabricating, natural or synthetic, biomaterials. Three main applications of such microfluidics-produced biomaterials can be identified: delivery of (biological) compounds and/or cells; enrichment of rare primary cells; and bioprinting [130]. Many of these systems are based on droplets, a rapidly growing subfield within microfluidics. Droplets are finely controlled emulsion objects generated by microfluidic stream breaks [131,132], existing either physically entrapped in arrays [133-135] or free in suspension [132,136,137]. As opposed to conventional methods to produce droplets, microfluidics-generated droplets can be highly monodisperse, easily engineered in geometry and content, and available for modular arrangements [131,132], owing to technical possibilities that allow precise generation, handling $[138,139]$ and dispensing [140-142].

\subsection{Biomaterials for delivery of biological compounds}

While the number of therapeutic agents including antibiotics, growth factors, small molecules and other drugs is increasing, their efficient, controlled and targeted delivery to the body remains a challenge. Application of small-sized particles as delivery vehicles offers solutions for some of the challenges, including issues with solubility of complex molecules, amounts to be delivered and control over release. Small particles can be used for surface bulk binding of the molecules, with their large specific surface area allowing loading of large amounts and multicomponent materials with controlled composition that can be used to control delivery dynamics. Drug carrier production using microfluidic droplet generation is considered an interesting alternative to other methods of microparticle production such as spray-drying, as it allows production of particles with a size below $100 \mathrm{~nm}[143,144]$. In particular structures such as polymersomes, prepared from water-oil-water templates and having either single, or multiple hydrogel cores, allow complex compartmentalization inside the droplets. This configuration ensures stability and protection to degradation while granting a sustainable release through the diffusion barrier constituted by the lipid bilayer [145].

Valencia et al. [146] developed a fully integrated system, using up to 15 different polymeric nanoparticle precursors in different ratios, with a multi-inlet micromixer to allow for programmable and systematic combinatorial mixing before nanoprecipitation occurs (Fig. 8A). Further developments in this kind of platforms may involve increased automation, bringing together digitally programmable circuits with responsive, reliable valves support $[130,147]$. Droplet-fusion for combinatorial synthesis [148] and chitosan microparticles assembly [149] are examples of extensive possibilities that droplet generation offers in the development of carriers for controlled delivery of biologics.

To address the issues associated with handling and preservation of deliverable cell aggregates in the period between their production and implantation, Cha et al. [150] used droplet technology to develop gelatin-silica core-shell microgels as carriers of cardiac side population (CSP) cells. While methacrylate gelatin droplets were used as actual carriers, the silica shell acted as a protective coating that degrades under physiological condition, once injected into cardiac tissue.

\subsection{Biomaterials for cell selection and enrichment}

Besides delivery of compounds of interest, droplet microfluidics-generated materials can also be used as carriers of cells. As such, they not only provide a 3D matrix to the cells, but they can also be used as individual microenvironments inside which biological processes, such as cell proliferation, differentiation, ECM production, etc. can be independently regulated [88].

Successful culture of stem cells while retaining their purity and/ or pluri- or multipotency in vitro in quantities required for clinical use, has been one of the major challenges in the process of clinical implementation of cell therapies. Confined 3D culture systems in which cell-cell interactions can be controlled to a high extent are expected to provide a significant contribution to platforms forhigh throughput culture of stem cells. The scalability of autologous cell production may provide a strong boost to development of cell therapy strategies, including the expansion of stem cells from umbilical cord blood [151,152], culturing of islets of Langerhans [153] and replacement of ventricular myocytes in case of myocardial failure due to infarction [154], among other applications.

Currently, strategies for expanding stem cells include aggregation or synthetic carriers taking into account the adherent nature of cells within a number of relevant lineages [155-157]. In general, the basic requirements for creating a self-renewal cellular niche includes the presence of an ECM-like environment, availability of soluble factors, cell-to-cell contact along with mechanical forces at microscale [156]. As mentioned earlier, hydrogels can fulfill a number of these requirement. Therefore, microfluidic droplet formation can be a valuable tool for cell encapsulation, either in an aqueous phase or in a 3D hydrogel, enabling expansion scale-up microenvironment fine-tuning both in composition and in mass transfer kinetics, and release from labor-intensive replating of cell spheroids. [158-160]. Agarwal et al. [137] developed a microencapsulation system for 3D culture of pluripotent stem cells aiming to overcome 2D culture limitations. In this work, microcapsules with an aqueous core containing ES cells inside an alginate hydrogel shell, were systematically produced. This system enabled cell clustering and aggregate expansion within the construct, while retaining their stemness, as verified by gene expression of Oct-4, Sox2, Nanog and Klf2, as markers of pluripotency (Fig. 8B). Chan et al. [160] applied a similar system showing an enhanced osteogenic differentiation of hMSC spheroids inside double-emulsion droplets with an inner phase made of an alginate-arginine-gly cine-aspartic acid (-RGD) hydrogel. 

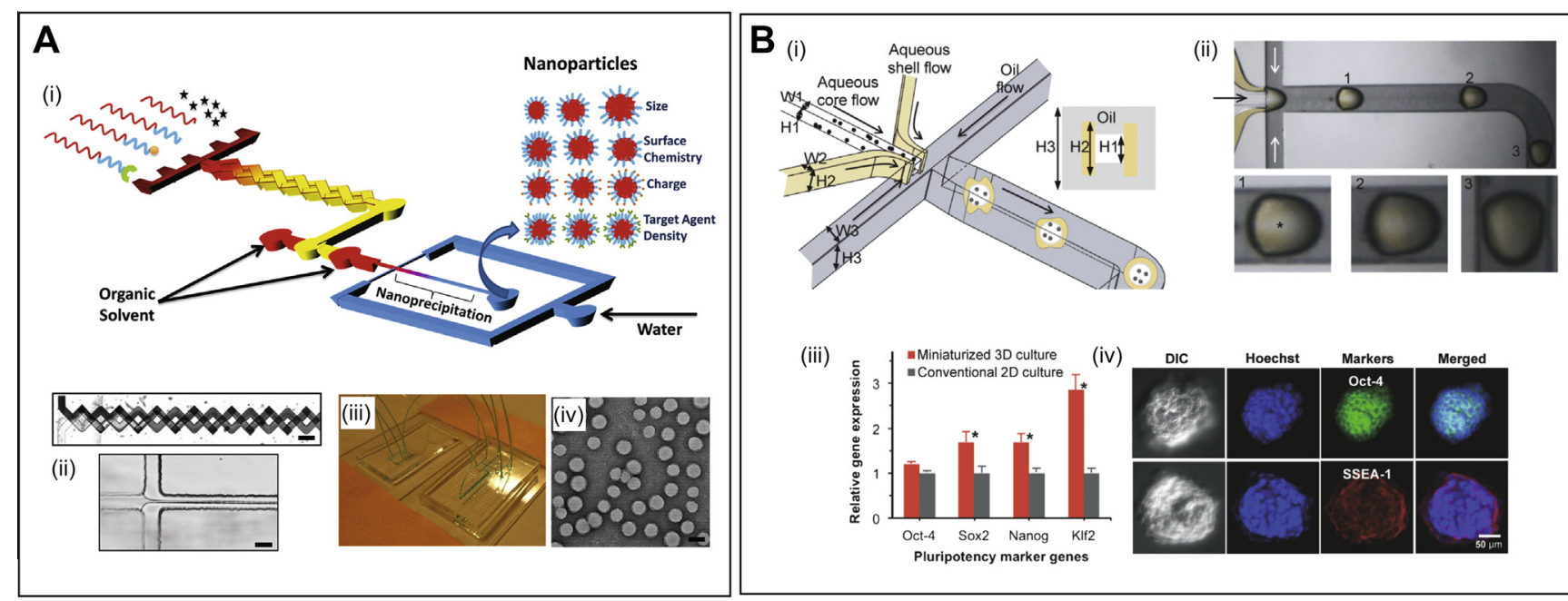

(iii)

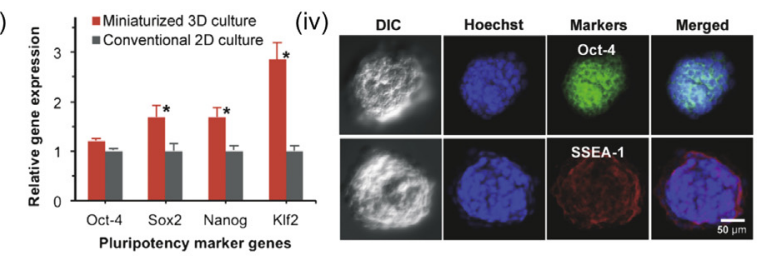

C

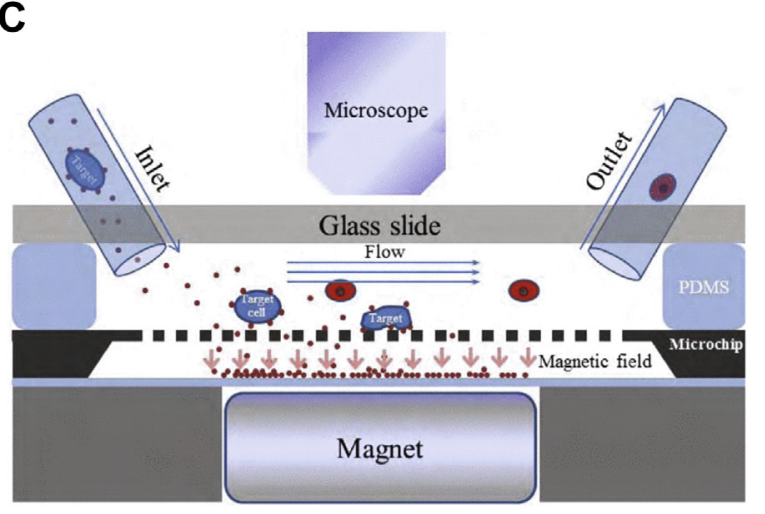

(i)

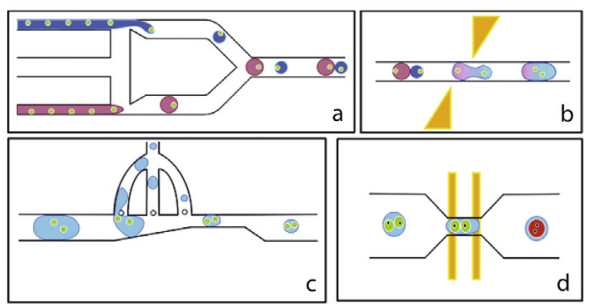

(ii)

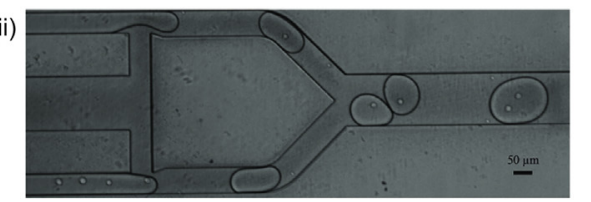

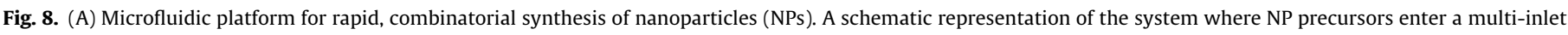

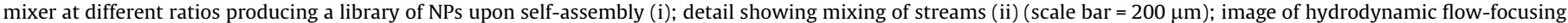

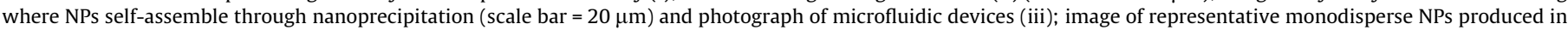

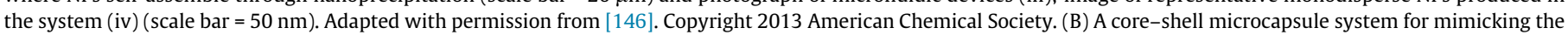

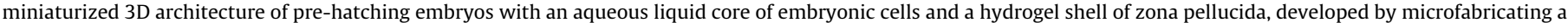

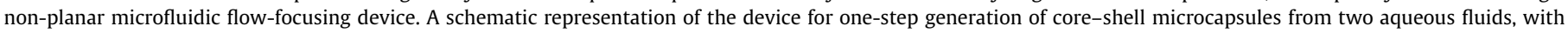

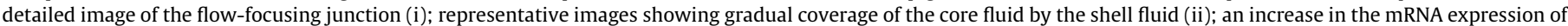

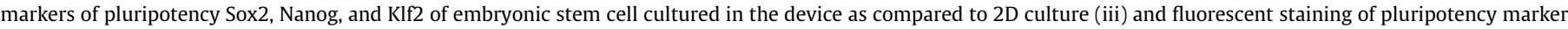

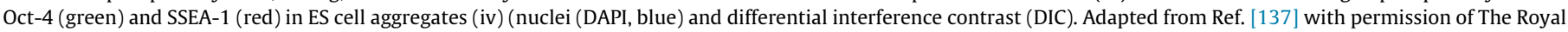

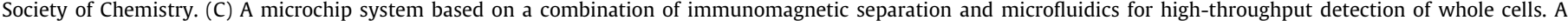

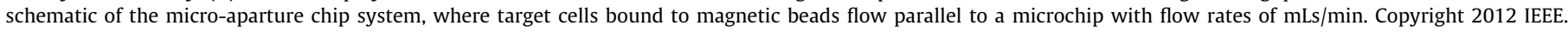

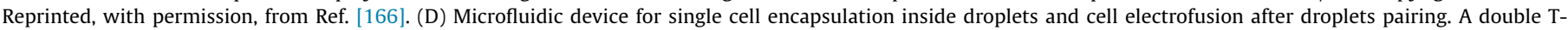

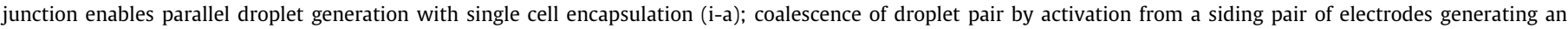

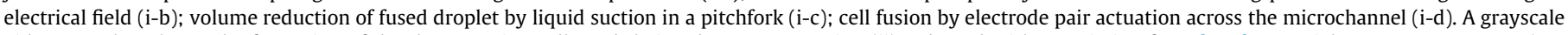

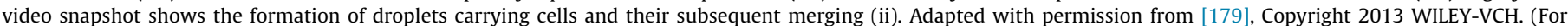
interpretation of the references to color in this figure legend, the reader is referred to the web version of this article.)

In addition to cell expansion strategies, relevant to cell therapy and regenerative medicine approaches, enrichment of rare or difficult to harvest types of cells can also be achieved using microfluidic tools. For example, microfluidic arrays have been used to concentrate cells in order to support cancer cell detection with the aim to achieve personalized early cancer prognosis based on circulating tumor cells (CTCs) assessment of their sensitivity to anticancer drugs [161,162]. Others have demonstrated the isolation of functional cardiomyocytes from heterogenous cell mixtures [163], leukocytes collection from blood fractions [164], and MSCs selection from amniotic fluid [165].

Targeting the isolation of rare cells, such as CTCs, Chun-Li et al. [166] developed a microfluidic chip for enrichment and analysis of whole cells. In the system, the target cells, bound to immunomagnetic beads were flown parallel to a porous wall while being actuated by a magnetic field, and retrieved by disabling the magnetic field (Fig. 8C). The system was successfully validated for detecting breast (MCF-7) and lung (A549) cancer cells in culture reaching yields up to $97 \%$ at $1 \mathrm{ml} / \mathrm{min}$ flow rate and a concentration as low as $0.8 \mathrm{cell} / \mathrm{ml}$. In a similar device setup by Cooper et al. [167], rare pathogen cells could be detected in small volume of human blood samples, assisted by ligand-coated magnetic beads, but instead of being caged in microwells, they were spread into a thin layer, allowing optical detection.

Efforts have also been invested in selection and handling of single cells. Selective single cells isolation has become available through the combined use of fluidic regimes and biomolecular chemistry technologies [168], or more simply through geometrical displacement and positioning [169]. Delicate handling of cells has now become possible by incorporation of non-invasive techniques such as optical tweezers [170,171] and dielectrophoresis $[172,173]$, or through immunomagnetic probes targeting different cell populations $[166,174,175]$. Ability to select and handle single cells allows for the use of unique derivation of genetic material 
by directed transfection [176], or directly by electrofusion [177-179]. For example, Schoeman et al. [179] engineered a device capable of encapsulating single cells inside droplets generated in parallel, which are paired in a second step and merged by the action of an electrical field. The resulting droplet is then reduced in volume by content suction, bringing the cells closer to one another in order to fuse and form a hybridoma while passing through an actuating pair of electrodes in the channel (Fig. 8D).

As summarized by Shields et al. [180], active systems for cell sorting make use of external stimuli (e.g., acoustic, electric, magnetic, and optical) to impose forces to displace cells, whereas passive systems rely on inertial forces, filters, and adhesion mechanisms. Microfluidic devices are suitable for both types of systems, as is demonstrated by examples of systems, utilizing geometrical fluid barriers [181-183], hydrodynamic forces [184], filtering methods [185], dielectric- [186-188] and magnetic material properties [80,189], acoustics [190] and optics [191].

\subsection{Building blocks for bioprinting}

Additive manufacturing, also known as 3D printing, is a technology that enables building of 3D structures from natural or synthetic materials. This technology has attracted much attention because it allows high level of control over properties of the structures, at different length scales. In the early days of additive manufacturing, many available techniques suffered from a limited resolution. However, it is now possible to directly produce structures with controlled topographical features at the submicron scale, or to perform bioprinting using single cells, clearly demonstrating the potential value of microfluidic systems herein. A combination of additive manufacturing and microfluidics can be seen from different perspectives, including: (1) application of additive manufacturing to build microfluidic devices for biomedical applications; (2) building of structures inside the microfluidic compartments, preferably prior to assembly of components, and fluid connection; and (3) using the microfluidics as an additive manufacturing tool.

Only few examples exist of additive manufacturing techniques being directly used to build microfluidic devices. Hamid et al. [192], for example, developed an integrated additive manufacturing instrument to allow multiple operations leading to direct printing of cell-laden microfluidic chips. The motorized setup, containing four heads, was capable of alternating between dispensing of a photopolymerizable-polymer, its exposure to UV-light and crosslinking, and dispensing of the biological content and application of gas plasma treatment to functionalise the surface for later bonding of the lid.

Undoubtedly, additive manufacturing, rapidly becoming an affordable technique to many research laboratories will be more frequently used for production of microfluidic devices in the future [193]. Along with this, new polymers (including transparent ones, and polymers allowing higher resolution manufacturing) suitable for additive manufacturing, are becoming available, making this technique a serious alternative to standard lithographic processes for building microfluidic platforms. A representative example was given by Erkal et al. [194], who designed a 3D printed device with a receiving port that fits with commercially available standard electrodes to analyze the conditions and contents of the fluid inside the device. Another design embedded a transwell plate for sample collection to analyze oxygen tension in a stream of flowing red blood cells, as well as measuring the level of ATP release (Fig. 9A).

To address the challenge of vascularization within large tissue constructs, Zhang et al. [195] employed additive manufacturing to build a blood vessel-like microfluidic structure, which was then embedded inside the bulk material. To this end, alginate and chitosan hydrogels were used for direct printing of the channels with a wall thickness below $200 \mu \mathrm{m}$. The printed microfluidic network was able to support media perfusion both outside and embedded in bulk hydrogels to support cell viability.

Stereolithography is an interesting additive manufacturing technique for producing transparent, biocompatible, fully computer designed microfluidic devices for cell culture [16], although the number of gas-permeable photopolymerizable resins is limited.

While additive manufacturing has not been exploited to its maximum extent for building the entire microfluidic devices, many interesting examples exist of materials produced using additive manufacturing that have been integrated into microfluidic platforms. Snyder et al. [196] applied direct cell writing, using cell suspension in Matrigel at a 1:1 ratio for drawing a pattern that was later incorporated into a perfused microfluidic chamber. A combination of hepatocytes and epithelial cells was used in a model where anti-radiation drug treatments were tested through the compartments defined by the printed soft biomaterials. In another study, Lee et al. [12] used inkjet-printed micropatterns of a composite material containing biphasic calcium phosphate nanoparticles and poly(D,L-lactic-co-glycolic acid) (P(D,L)LGA). This multiplex device was built with the aim to better understand phenomena governing implant-related wound healing while preventing bacterial infection. The model was shown to be useful for monitoring the formation of mineralized ECM by osteoblasts, and prevention of biofilm formation upon exposure of Staphylococcus epidermidis to an antibiotic.

In addition to the so far presented examples of additive manufacturing techniques to build (parts of) microfluidic devices, it is important to discuss the possibilities of the microfluidic devices to print materials, or, at least, to provide continuous or discrete jetting of materials through a coordinate control of the flow, with droplet generation being particularly interesting in this context. This is a logical application of microfluidics, because also this technique can offer a close control over the properties of complex (multiphase) fluidic dynamics over a diversity of sources, towards the synthesis of chemically and structurally defined functional biomaterials. An interesting example of application of microfluidics to produce functional biomaterials with tuned properties was given by Shum et al. [197] (Fig. 9B) who synthetized mesoporous hydroxyapatite through double emulsion droplets (used as individual microreactors), adjustable both in size and geometry. This platform allowed on-demand regulation of droplet composition, tuning therewith their porosity and compactness, and consequently the homogeneity of the ceramic powder produced. Another study, by Kitagawa et al. [198], presented a multilayered microfluidic devices with a micronozzle array structure allowing the production of hollow alginate hydrogel microfibers. This system allowed culture of neuron-like PC12 cells in the parallel regions, which proliferated and formed linear intercellular networks (Fig. 9C).

The ability of microfluidic systems to handle living tissue, or cell niches, under mild-conditions, combined with well-established hydrogel processing techniques, can be further exploited to make microfluidic technology a key component in new bioprinting developments involving direct deposition of cells. When employed upstream of any type of nozzle used for additive manufacturing, microfluidics offers the possibility to deliver more than just single-cells as building blocks, and also more than just chemically engineered hydrogels. Instead, as described in previous sections, combinations of both materials can deliver more complex building blocks for constructs produced using additive manufacturing. This is an important consideration, as currently available additive manufacturing tools for single-cell printing do not reach further than printing of $2 \mathrm{D}$ patterns, despite efforts placed in improving nozzle 

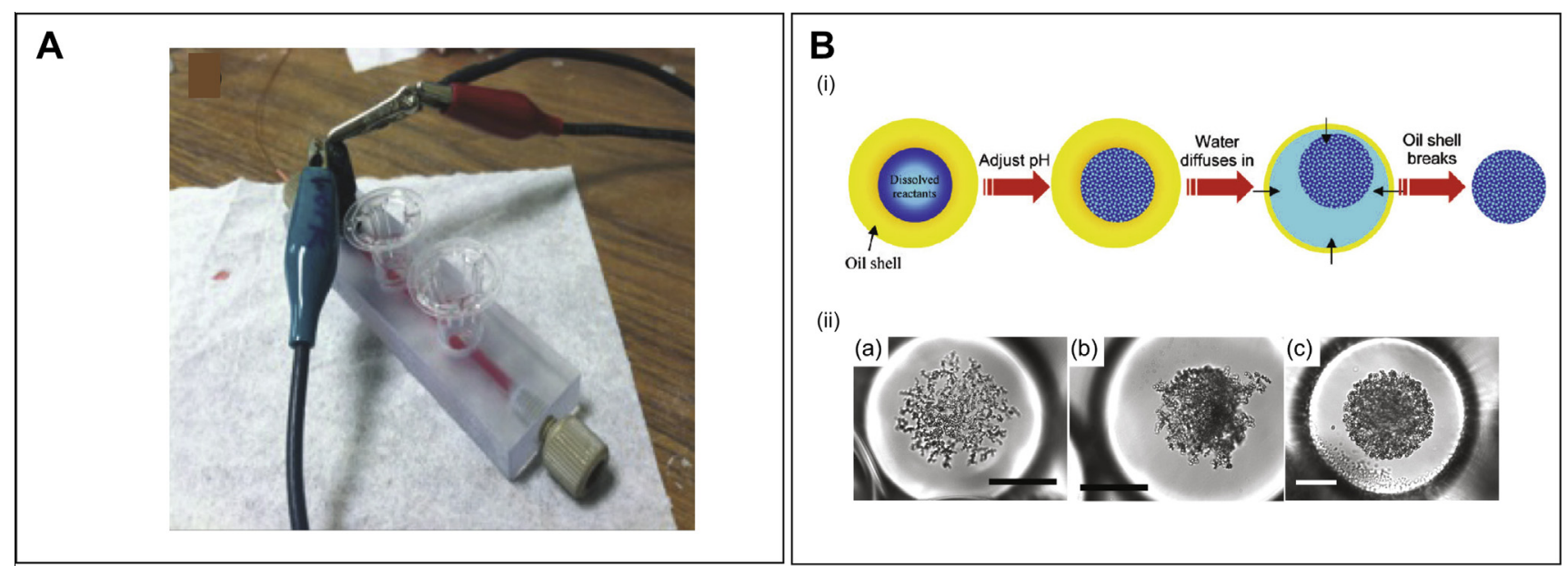

(ii)
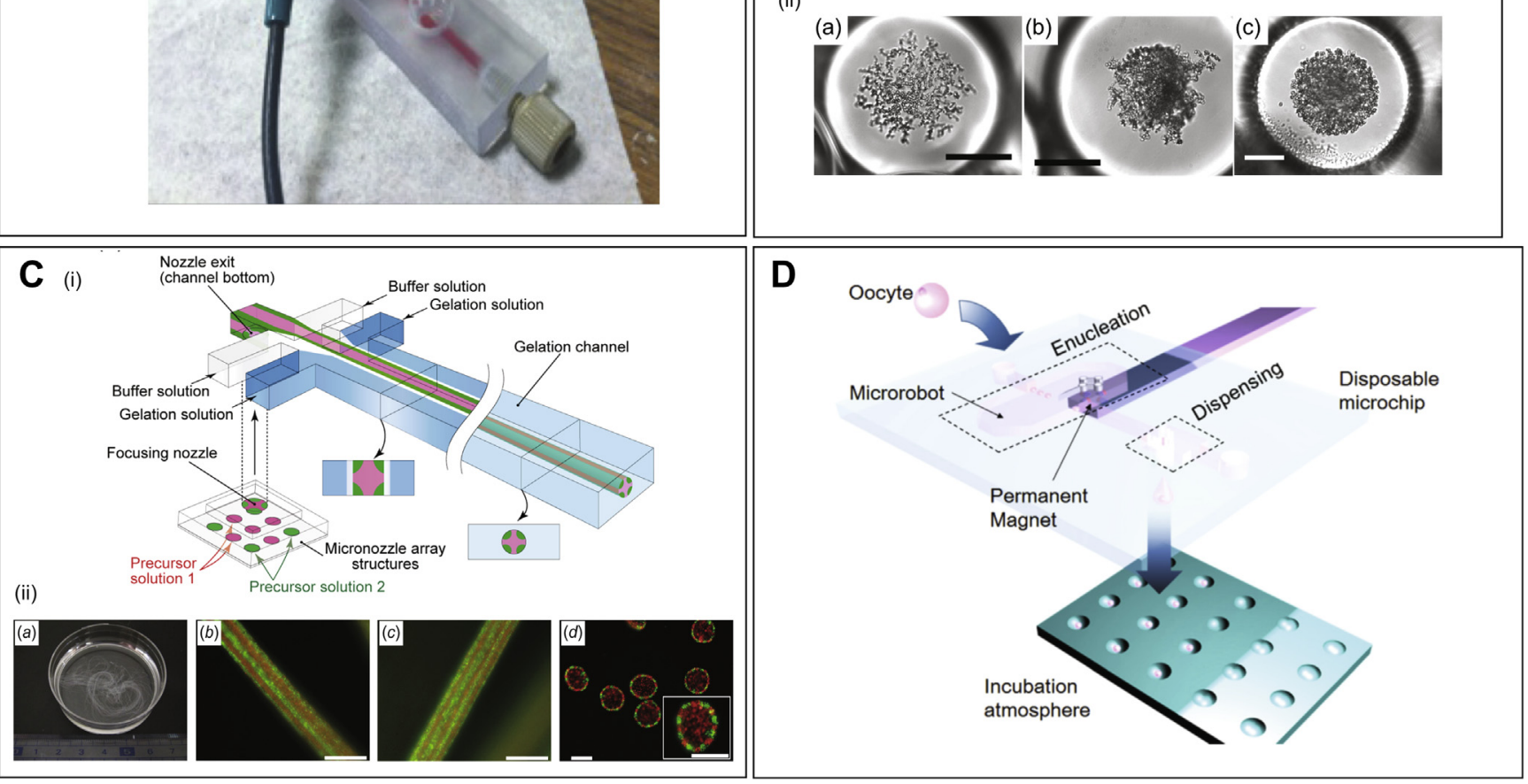

Fig. 9. (A) A transwell fluidic device for correlation of oxygen tension and adenosine triphosphate release. Picture of the assembled device with red blood cells being pumped through the system. Adapted from Ref. [194] with permission of The Royal Society of Chemistry. (B) Synthesis of mesoporous hydroxyapatite using double-emulsion droplets as microreactors. The inner drops of the double emulsion consist of an aqueous solution of calcium nitrate and phosphoric acid, as calcium and phosphate precursors, respectively. The outer shell contains inert oil (i); optical microscope images of hydroxyapatite aggregates formed from precursor solutions with calcium nitrate and phosphoric acid concentrations of 0.1 and $0.06 \mathrm{M}$ (ii-a); 0.5 and $0.3 \mathrm{M}$ (ii-b); and 1 and $0.6 \mathrm{M}$ (ii-c), respectively. Adapted with permission from Ref. [197]. Copyright 2009 American Chemical Society. (C) A microfluidic device with a micronozzle array structure for developing hydrogel microfibers with complex cross-sectional morphologies to be used for guiding network formation of neuronal cells. A schematic showing the device in which hydrogel precursor solutions with different compositions, with or without rat pheochromocytoma (PC12) cells, are continuously introduced into the microchannel along with the buffer and gelation solutions (i); a photograph of an eight-region hydrogel fiber (ii-a), fluorescent micrographs of four- (ii-b) and eight (ii-c) region hydrogel fiber and of a thin cross-section of an eight-region fiber (ii-d) produced in the device (scale bar $=100 \mu \mathrm{m}$ ). Adapted from Ref. [198]. (D) A dispensing system for single oocytes using air ejection. On-chip cell enucleation and single-cell dispensing over an array that can be used for further cell culture. Reprinted with permission from Ref. [203], Copyright 2013, AIP Publishing LLC. (For interpretation of the references to color in this figure legend, the reader is referred to the web version of this article.)

designs and positioning stages [199,200], although such 2D patterns have proven to be useful for single-cell genomic analysis [199], among others [201,202]. In this context, microfluidic solutions may be advantageous for separation and isolation of cells ahead of being expelled through the nozzle orifice. For instance, coupling impedance spectroscopy to the dispensing chip enables a more robust detection at higher particle velocity than optical methods [200]. Feng et al. [203] employed such technique to dispense oocytes in a single-cell array for culturing and viability characterization, demonstrating its further use in cloning (Fig. 9D).

Taken together, both additive manufacturing and microfluidics are becoming increasingly recognized as useful techniques in biomedical research, and smart combinations of the two may synergistically advance the state-of-the-art in the field.

\section{General conclusions and outlook}

This review discussed a number of developments in the field of microfluidics relevant to biomedical research, with an emphasis on biomaterials. Microfluidics can support biomedical research by either accelerating the throughput of screening, or by increasing the complexity of in vitro models in order to more closely resemble the in vivo microenvironment. The development of highthroughput and combinatorial screening of physical and chemical cues, known to interfere in biological processes, was presented here as an example of the important contribution of microfluidics to the biomaterial field. Further, microfluidics offers tools for the in-depth study of physiological processes in in vivo-like microenvironments, a feature that is not possible using conventional cell culture approaches. Lastly, microfluidic systems are intensively explored as microfactories for novel, complex, synthetic or natural biomaterials, or combinations thereof.

It is important to note that microfluidics, originating from the field of MEMS, is a strongly technology-driven development. Technological advancements in the field of microfluidics progress at a pace that the typically conservative biomedical field struggles to match. This may, in part, explain why microfluidic devices have not yet caused a paradigm shift in the way biomedical research is executed, despite almost endless technological possibilities. 
Indeed, in terms of technological development, microfluidics has reached a high level of maturity, with numerous companies producing microfluidic devices for well-established applications, such as high-throughput compound analyzes and rapid diagnostic tests. Although examples exist of such platforms that are also used in the biomedical field in a relatively standard manner, such as for cell sorting, concentration, etc. [204-208], they are still scarce and lack mainstream applications to trigger extensive industry involvement.

As a result of the mismatch between the technological advancements and the actual implementation of microfluidic systems, the approach towards the development of new systems is now changing from "we make it because we can" to "we make it because the need exists". This, however, requires a truly multidisciplinary approach to the design, whereby the input from the end-users is of fundamental importance. On the other hand, researchers in the biomedical field, such as biomaterials, are facing a situation in which new clinical treatments have to be more efficient, and developed more rapidly, both at the same time. This directly implies that the existing research tools are not sufficient anymore, and that new tools need to be developed. We envision that in the future, combined efforts from the fields of microfluidics and biomedical technology will revolve around the development of systems that offer both a better predictability for the in vivo situation, and an increased screening throughput.

The first steps towards this aim have been made. The unique ability of microfluidic systems to allow cell culture inside immobilised hydrogels for highly stratified tissue-like constructs, along with fine control over supplying fluidics, and complex structural layering, makes closer mimicking of an in vivo microenvironment a reality. In addition to compartmentalization, controlled interconnection between compartments allows for the study of systemic effects, something that is not possible with any other in vitro platform. Therefore, current organ-on-chip models are not only useful for studying malfunctioning of a single component of an organ, and its associated drug therapy, but they also enable studying of complex process such as tumor metastasis and regeneration using different strategies.

An important issue that remains a challenge in such systems is the availability of adequate and reliable readouts. Due to the low handling volumes required for microfluidics, the large majority of conventional quantitative methods used as standards in molecular cell biology are not directly applicable to such microsystems. In microfluidic systems, conventional quantitative techniques often operate at the lower limits of sensitivity. Furthermore, it is difficult to retrieve a sample or to integrate a sensor, and even when this is possible, valuable spatial information is lost. Attempts have been made to adapt the conventional analytical techniques to the requirements of microfluidics, for example by developing customized interfaces, or by the use of single-cell or low cell number genomic or proteomic analyzes [5,209,210]. However, microfluidic platforms, as with many other high-throughput screening platforms, will continue to largely rely on biomolecular engineering techniques coupled with microscopy-based imaging. Although downscaling of assays is a big challenge, the possibility to perform experiments with a much higher throughput in microfluidic devices is one part of the solution. In any case, researchers in the biomedical field will need to accept that alternative readouts are inherently connected to microfluidics-based systems. This is probably only a matter of time, once the evidence for validity and reliability of such alternative assays is provided. On the other hand, small volumes and low amounts of materials/cells offers new possibilities for personalized medicine, where clinically relevant microfluidic in vitro models will be developed with patient's own cells, or specific combinations of genetic mutations, etc.
We also expect that biomaterial development will further benefit from the application of microfluidics, alone and in combination with other production systems. In particular, microfluidic systems are expected to aid development of biomaterials with closely controlled properties. Microfluidics will not only be used for the relatively simple generation of gradients within hydrogels, but its use will extend to other material types with various levels of physico-chemical complexity. This will require development of more modular systems, where biomaterials can be introduced into the system using other techniques prior to the assembly of the platform. Such examples include micromolding in capillaries, photolithography, two-photon polymerization, fiber growth, cellular textile mono- and multi-layers, spheroids, etc.

Furthermore, hybrid set-ups, combining microfluidic parts such as cell-supporting hydrogel constructs, and robotic components from 3D printers, such as combinatorial nozzle platforms, may enable the construction of realistic, hierarchical macroscale functional living tissue mimics. Together with the integration of other biomaterial components, ranging from protein aggregates, polymers, or ceramics, into such mimics, it is very likely that robust in vivo disease and regenerative models will be further developed. Furthermore, one can envision that such sophisticated mimics would also become available as implantable constructs.

In summary, this review has shown that the developments in the field of microfluidics are not solely technical advancements, but are also truly valuable tools for biomedical research. Therefore, it is conceivable that they may in the future successfully replace the minimalistic gold standard of flat plastic substrates supporting monolayer cultures. To this end, such systems will have to become more accessible to the average research laboratory. Needless to mention, these developments will also lead to new challenges, in particular when it comes to the availability of reliable assays. Furthermore, the predictive value of any future screening system will need to have a proven higher level of output information than what conventional, simpler systems currently offer. We believe that a more collaborative development of new platforms, with microfluidics engineers as technology providers, and biomedical scientists as users, is imperative for reaching this goal.

\section{Acknowledgements}

D.B. gratefully acknowledges the financial support of the NIRM (Netherlands Institute of Regenerative Medicine). This research has been in part made possible with the support of the Dutch Province of Limburg.

\section{References}

[1] S. Kobel, M.P. Lutolf, Biomaterials meet microfluidics: building the next generation of artificial niches, Curr. Opin. Biotechnol. 22 (2011) 690-697.

[2] C.J. Bettinger, J.T. Borenstein, Biomaterials-based microfluidics for engineered tissue constructs, Soft Matter 6 (2010) 4999-5015.

[3] P. Habibovic, T. Woodfield, K. de Groot, C. van Blitterswijk, Predictive value of in vitro and in vivo assays in bone and cartilage repair-What do they really tell us about the clinical performance?, Adv Exp. Med. Biol. 585 (2006) 327360.

[4] G.M. Whitesides, The origins and the future of microfluidics, Nature 442 (2006) 368-373.

[5] S.F. Mao, D. Gao, W. Liu, H.B. Wei, J.M. Lin, Imitation of drug metabolism in human liver and cytotoxicity assay using a microfluidic device coupled to mass spectrometric detection, Lab Chip 12 (2012) 219-226.

[6] P. Domachuk, K. Tsioris, F.G. Omenetto, D.L. Kaplan, Bio-microfluidics: biomaterials and biomimetic designs, Adv. Mater. 22 (2010) 249-260.

[7] E. Berthier, E.W. Young, D. Beebe, Engineers are from PDMS-land, biologists are from polystyrenia, Lab Chip 12 (2012) 1224-1237.

[8] A. van Reenen, A.M. de Jong, J.M. den Toonder, M.W. Prins, Integrated lab-onchip biosensing systems based on magnetic particle actuation-a comprehensive review, Lab Chip 14 (2014) 1966-1986.

[9] S. Choi, M. Goryll, L.Y.M. Sin, P.K. Wong, J. Chae, Microfluidic-based biosensors toward point-of-care detection of nucleic acids and proteins, Microfluid. Nanofluid. 10 (2011) 231-247. 
[10] S. Kumar, S. Kumar, M.A. Ali, P. Anand, V.V. Agrawal, R. John, et al., Microfluidic-integrated biosensors: prospects for point-of-care diagnostics, Biotechnol. J. 8 (2013) 1267-1279.

[11] M. Zhan, L. Chingozha, H. Lu, Enabling systems biology approaches through microfabricated systems, Anal. Chem. 85 (2013) 8882-8894.

[12] J.-H. Lee, Y. Gu, H. Wang, W.Y. Lee, Microfluidic 3D bone tissue model for high-throughput evaluation of wound-healing and infection-preventing biomaterials, Biomaterials 33 (2012) 999-1006.

[13] Y. Zheng, J. Chen, M. Craven, N.W. Choi, S. Totorica, A. Diaz-Santana, et al., In vitro microvessels for the study of angiogenesis and thrombosis, Proc. Natl. Acad. Sci. U.S.A. 109 (2012) 9342-9347.

[14] A.K. Au, W. Lee, A. Folch, Mail-order microfluidics: evaluation of stereolithography for the production of microfluidic devices, Lab Chip 14 (2014) 1294-1301.

[15] O.H. Paydar, C.N. Paredes, Y. Hwang, J. Paz, N.B. Shah, R.N. Candler, Characterization of 3D-printed microfluidic chip interconnects with integrated O-rings, Sens. Actuators, A 205 (2014) 199-203.

[16] A.K. Au, N. Bhattacharjee, L.F. Horowitz, T.C. Chang, A. Folch, 3D-printed microfluidic automation, Lab Chip 15 (2015) 1934-1941.

[17] M. Zhang, J. Wu, L. Wang, K. Xiao, W. Wen, A simple method for fabricating multi-layer PDMS structures for 3D microfluidic chips, Lab Chip 10 (2010) 1199-1203.

[18] D.M. Titmarsh, J.E. Hudson, A. Hidalgo, A.G. Elefanty, E.G. Stanley, E.J Wolvetang, et al., Microbioreactor arrays for full factorial screening of exogenous and paracrine factors in human embryonic stem cell differentiation, PLoS One (2012) 7.

[19] B.-H. Chueh, D. Huh, C.R. Kyrtsos, T. Houssin, N. Futai, S. Takayama, Leakagefree bonding of porous membranes into layered microfluidic array systems, Anal. Chem. 79 (2007) 3504-3508.

[20] B.R. Flachsbart, K. Wong, J.M. Iannacone, E.N. Abante, R.L. Vlach, P.A. Rauchfuss, et al., Design and fabrication of a multilayered polymer microfluidic chip with nanofluidic interconnects via adhesive contact printing, Lab Chip 6 (2006) 667-674.

[21] M. Gong, B.R. Flachsbart, M.A. Shannon, P.W. Bohn, J.V. Sweedler, Fluidic communication between multiple vertically segregated microfluidic channels connected by nanocapillary array membranes, Electrophoresis 29 (2008) 1237-1244.

[22] X. Chen, L. Zhang, H. Li, J. Sun, H. Cai, D. Cui, Development of a multilayer microfluidic device integrated with a PDMS-cellulose composite film for sample pre-treatment and immunoassay, Sens. Actuators, A 193 (2013) 5458.

[23] S. Haeberle, R. Zengerle, Microfluidic platforms for lab-on-a-chip applications, Lab Chip 7 (2007) 1094-1110.

[24] O. Strohmeier, M. Keller, F. Schwemmer, S. Zehnle, D. Mark, F. von Stetten, et al., Centrifugal microfluidic platforms: advanced unit operations and applications, Chem. Soc. Rev. (2015).

[25] G. Velve-Casquillas, M. Le Berre, M. Piel, P.T. Tran, Microfluidic tools for cell biological research, Nano Today 5 (2010) 28-47.

[26] S. Le Gac, A. van den Berg, Single cells as experimentation units in lab-on-achip devices, Trends Biotechnol. 28 (2010) 55-62.

[27] A.R. Wheeler, W.R. Throndset, R.J. Whelan, A.M. Leach, R.N. Zare, Y.H. Liao, et al., Microfluidic device for single-cell analysis, Anal. Chem. 75 (2003) 3581-3586.

[28] D.D. Carlo, L.Y. Wu, L.P. Lee, Dynamic single cell culture array, Lab Chip 6 (2006) 1445-1449.

[29] S.L. Faley, M. Copland, J. Reboud, J.M. Cooper, Cell chip array for microfluidic proteomics enabling rapid in situ assessment of intracellular protein phosphorylation, Biomicrofluidics (2011) 5 .

[30] J. Akagi, J. Skommer, A. Matuszek, K. Takeda, Y. Fujimura, K. Khoshmanesh, et al., Multivariate analysis of apoptotic markers versus cell cycle phase in living human cancer cells by microfluidic cytometry, Proc. SPIE (2013) 8615 $10.1117 / 12.2001474$

[31] Y.-Y. Chiang, J. Stewart, C. Gizewski, P. Ehrhard, D. Janasek, J. West, Recording signal transduction dynamics with unprecedented temporal resolution, in: The Sixteenth International Conference on Miniaturized Systems for Chemistry and Life Sciences ( $\mu$ TAS 2012), Japan, 2012.

[32] M. Junkin, S. Tay, Microfluidic single-cell analysis for systems immunology, Lab Chip 14 (2014) 1246-1260.

[33] D. Wlodkowic, S. Faley, M. Zagnoni, J.P. Wikswo, J.M. Cooper, Microfluidic single-cell array cytometry for the analysis of tumor apoptosis, Anal. Chem. 81 (2009) 5517-5523.

[34] M. Chabert, J.L. Viovy, Microfluidic high-throughput encapsulation and hydrodynamic self-sorting of single cells, Proc. Natl. Acad. Sci. U.S.A. 105 (2008) 3191-3196.

[35] D.J. Eastburn, A. Sciambi, A.R. Abate, Ultrahigh-throughput mammalian single-cell reverse-transcriptase polymerase chain reaction in microfluidic drops, Anal. Chem. 85 (2013) 8016-8021.

[36] E. Brouzes, M. Medkova, N. Savenelli, D. Marran, M. Twardowski, J.B. Hutchison, et al., Droplet microfluidic technology for single-cell highthroughput screening, Proc. Natl. Acad. Sci. U.S.A. 106 (2009) 14195-14200.

[37] I.K. Dimov, G. Kijanka, Y. Park, J. Ducree, T. Kang, L.P. Lee, Integrated microfluidic array plate (iMAP) for cellular and molecular analysis, Lab Chip 11 (2011) 2701-2710.

[38] K. Yang, S. Han, Y. Shin, E. Ko, J. Kim, K.I. Park, et al., A microfluidic array for quantitative analysis of human neural stem cell self-renewal an differentiation in three-dimensional hypoxic microenvironment, Biomaterials 34 (2013) 6607-6614.

[39] H.Y. Wang, N. Bao, C. Lu, A microfluidic cell array with individually addressable culture chambers, Biosens. Bioelectron. 24 (2008) 613-617.

[40] M. Nourmohammadzadeh, J.F. Lo, M. Bochenek, JE. Mendoza-Elias, Q Wang, Z. Li, et al., Microfluidic array with integrated oxygenation control for realtime live-cell imaging: effect of hypoxia on physiology of microencapsulated pancreatic islets, Anal. Chem. 85 (2013) 11240-11249.

[41] E. Kang, Y.Y. Choi, Y. Jun, B.G. Chung, S.H. Lee, Development of a multi-layer microfluidic array chip to culture and replate uniform-sized embryoid bodies without manual cell retrieval, Lab Chip 10 (2010) 2651-2654.

[42] J.L. Wilson, S. Suri, A Singh, C.A. Rivet, H. Lu, T.C. McDevitt, Single-cell analysis of embryoid body heterogeneity using microfluidic trapping array, Biomed. Microdevices 16 (2014) 79-90.

[43] K. Chung, Y. Kim, J.S. Kanodia, E. Gong, S.Y. Shvartsman, H. Lu, A microfluidic array for large-scale ordering and orientation of embryos, Nat. Methods 8 (2011). 171-U03.

[44] E. Bier, Drosophila, the golden bug, emerges as a tool for human genetics, Nat. Rev. Genet. 6 (2005) 9-23.

[45] M.C. Leung, P.L. Williams, A. Benedetto, C. Au, K.J. Helmcke, M. Aschner, et al., Caenorhabditis elegans: an emerging model in biomedical and environmental toxicology, Toxicol. Sci. 106 (2008) 5-28.

[46] D. St Johnston, The art and design of genetic screens: Drosophila melanogaster, Nat. Rev. Genet. 3 (2002) 176-188.

[47] T.J. Levario, M. Zhan, B. Lim, S.Y. Shvartsman, H. Lu, Microfluidic trap array for massively parallel imaging of Drosophila embryos, Nat. Protoc. 8 (2013) 721 736.

[48] J.A. Carr, A. Parashar, R. Gibson, A.P. Robertson, R.J. Martin, S. Pandey, A microfluidic platform for high-sensitivity, real-time drug screening on $C$. elegans and parasitic nematodes, Lab Chip 11 (2011) 2385-2396.

[49] S.E. Hulme, S.S. Shevkoplyas, A.P. McGuigan, J. Apfeld, W. Fontana, G.M. Whitesides, Lifespan-on-a-chip: microfluidic chambers for performing lifelong observation of C. elegans, Lab Chip 10 (2010) 589-597.

[50] S.R. Lockery, S.E. Hulme, W.M. Roberts, K.J. Robinson, A. Laromaine, T.H. Lindsay, et al., A microfluidic device for whole-animal drug screening using electrophysiological measures in the nematode C. elegans, Lab Chip 12 (2012) 2211-2220.

[51] E.M. Wielhouwer, S. Ali, A. Al-Afandi, M.T. Blom, M.B. Olde Riekerink, C. Poelma, et al., Zebrafish embryo development in a microfluidic flow-through system, Lab Chip 11 (2011) 1815-1824.

[52] J.P. Dexter, M.B. Tamme, C.H. Lind, E.-M.S. Collins, On-chip immobilization of planarians for in vivo imaging, Sci. Rep. (2014) 4.

[53] S. Kim, H.J. Kim, N.L. Jeon, Biological applications of microfluidic gradient devices, Integr. Biol.-UK 2 (2010) 584-603.

[54] E. Berthier, D.J. Beebe, Gradient generation platforms: new directions for an established microfluidic technology, Lab Chip 14 (2014) 3241-3247.

[55] E. Weibull, S. Matsui, M. Sakai, H. Andersson Svahn, T. Ohashi, Microfluidic device for generating a stepwise concentration gradient on a microwell slide for cell analysis, Biomicrofluidics 7 (2013) 064115.

[56] H. Kim, J. Ali, K. Phuyal, S. Park, M. Kim, Investigation of bacterial chemotaxis using a simple three-point microfluidic system, BioChip J. 9 (2015) 50-58.

[57] J.D. Wu, X. Wu, F. Lin, Recent developments in microfluidics-based chemotaxis studies, Lab Chip 13 (2013) 2484-2499.

[58] G.M. Walker, J. Sai, A. Richmond, M. Stremler, C.Y. Chung, J.P. Wikswo, Effects of flow and diffusion on chemotaxis studies in a microfabricated gradient generator, Lab Chip 5 (2005) 611-618.

[59] H. Somaweera, A. Ibragimov, D. Pappas, Generation of a chemical gradient across an array of 256 cell cultures in a single chip, Analyst 138 (2013) 55665571.

[60] M.J. Kim, K.H. Lim, H.J. Yoo, S.W. Rhee, T.H. Yoon, Morphology-based assessment of $\mathrm{Cd} 2+$ cytotoxicity using microfluidic image cytometry (microFIC), Lab Chip 10 (2010) 415-417.

[61] B. Harink, S. Le Gac, D. Barata, C. van Blitterswijk, P. Habibovic, Microfluidic platform with four orthogonal and overlapping gradients for soluble compound screening in regenerative medicine research, Electrophoresis 36 (2015) 475-484

[62] B.G. Chung, L.A. Flanagan, S.W. Rhee, P.H. Schwartz, A.P. Lee, E.S. Monuki, et al., Human neural stem cell growth and differentiation in a gradientgenerating microfluidic device, Lab Chip 5 (2005) 401-406.

[63] Y.Q. Zhang, W.J. Zhang, L.D. Qin, Mesenchymal-mode migration assay and antimetastatic drug screening with high-throughput microfluidic channel networks, Angew. Chem. Int. Ed. 53 (2014) 2344-2348.

[64] N. Gopalakrishnan, R. Hannam, G.P. Casoni, D. Barriet, J.M. Ribe, M. Haug, et al., Infection and immunity on a chip: a compartmentalised microfluidic platform to monitor immune cell behaviour in real time, Lab Chip 15 (2015) $1481-1487$.

[65] Y. Awwad, T. Geng, A.S. Baldwin, C. Lu, Single cell NF-кB dynamics under stimulant concentration gradient, Anal. Chem. 84 (2012) 1224-1228.

[66] T.F. Byrd Iv, L.T. Hoang, E.G. Kim, M.E. Pfister, E.M. Werner, S.E. Arndt, et al., The microfluidic multitrap nanophysiometer for hematologic cancer cell characterization reveals temporal sensitivity of the calcein-AM efflux assay, Sci. Rep.-UK 4 (2014) 5117.

[67] S. Paliwal, P.A. Iglesias, K. Campbell, Z. Hilioti, A. Groisman, A. Levchenko, MAPK-mediated bimodal gene expression and adaptive gradient sensing in yeast, Nature 446 (2007) 46-51. 
[68] H.J. Yoo, J. Park, T.H. Yoon, High throughput cell cycle analysis using microfluidic image cytometry ( $\mu$ FIC), Cytometry A 83A (2013) 356-362.

[69] E. Jastrzebska, S. Flis, A. Rakowska, M. Chudy, Z. Jastrzebski, A. Dybko, et al., A microfluidic system to study the cytotoxic effect of drugs: the combined effect of celecoxib and 5-fluorouracil on normal and cancer cells, Microchim. Acta 180 (2013) 895-901.

[70] R.O. Hynes, The extracellular matrix: not just pretty fibrils, Science 326 (2009) 1216-1219.

[71] J. Wu, Z. Mao, H. Tan, L. Han, T. Ren, C. Gao, Gradient biomaterials and their influences on cell migration, Interface Focus 2 (2012) 337-355.

[72] J. Almodovar, T. Crouzier, S. Selimovic, T. Boudou, A. Khademhosseini, C. Picart, Gradients of physical and biochemical cues on polyelectrolyte multilayer films generated via microfluidics, Lab Chip 13 (2013) 15621570.

[73] T.F. Didar, M. Tabrizian, Generating multiplex gradients of biomolecules for controlling cellular adhesion in parallel microfluidic channels, Lab Chip 12 (2012) 4363-4371.

[74] L.S.M. Teixeira, J. Patterson, F.P. Luyten, Skeletal tissue regeneration: where can hydrogels play a role?, Int Orthop. 38 (2014) 1861-1876.

[75] S. Cosson, S. Allazetta, M.P. Lutolf, Patterning of cell-instructive hydrogels by hydrodynamic flow focusing, Lab Chip 13 (2013) 2099-2105.

[76] C. Neils, Z. Tyree, B. Finlayson, A. Folch, Combinatorial mixing of microfluidic streams, Lab Chip 4 (2004) 342-350.

[77] P.J. Hung, P.J. Lee, P. Sabounchi, R. Lin, L.P. Lee, Continuous perfusion microfluidic cell culture array for high-throughput cell-based assays, Biotechnol. Bioeng. 89 (2005) 1-8.

[78] Y.H. Jang, M.J. Hancock, S.B. Kim, S. Selimovic, W.Y. Sim, H. Bae, et al., An integrated microfluidic device for two-dimensional combinatorial dilution, Lab Chip 11 (2011) 3277-3286.

[79] R. Sinha, S. Le Gac, N. Verdonschot, A. van den Berg, B. Koopman, J. Rouwkema, A medium throughput device to study the effects of combinations of surface strains and fluid-flow shear stresses on cells, Lab Chip 15 (2015) 429-439.

[80] D. Kilinc, A. Blasiak, J.J. O’Mahony, G.U. Lee, Low piconewton towing of CNS axons against diffusing and surface-bound repellents requires the inhibition of motor protein-associated pathways, Sci. Rep.-UK (2014) 4.

[81] J. Li, L. Zhu, M. Zhang, F. Lin, Microfluidic device for studying cell migration in single or co-existing chemical gradients and electric fields, Biomicrofluidics (2012) 6.

[82] K. Hattori, S. Sugiura, T. Kanamori, Microenvironment array chip for cell culture environment screening, Lab Chip 11 (2011) 212-214.

[83] Y. Yang, K. Kulangara, J. Sia, L. Wang, K.W. Leong, Engineering of a microfluidic cell culture platform embedded with nanoscale features, Lab Chip 11 (2011) 1638-1646.

[84] L. Wang, W. Liu, Y. Wang, J.-c. Wang, Q. Tu, R. Liu, et al., Construction of oxygen and chemical concentration gradients in a single microfluidic device for studying tumor cell-drug interactions in a dynamic hypoxia microenvironment, Lab Chip 13 (2013) 695-705.

[85] S. Garcia, R. Sunyer, A. Olivares, J. Noailly, J. Atencia, X. Trepat, Generation of stable orthogonal gradients of chemical concentration and substrate stiffness in a microfluidic device, Lab Chip (2015).

[86] J. Kim, D. Taylor, N. Agrawal, H. Wang, H. Kim, A. Han, et al., A programmable microfluidic cell array for combinatorial drug screening, Lab Chip 12 (2012) $1813-1822$.

[87] G.Y. Huang, L.H. Zhou, Q.C. Zhang, Y.M. Chen, W. Sun, F. Xu, et al., Microfluidic hydrogels for tissue engineering, Biofabrication 3 (2011) 012001.

[88] J.D. Wan, Microfluidic-based synthesis of hydrogel particles for cell microencapsulation and cell-based drug delivery, Polymers-Basel 4 (2012) 1084-1108.

[89] B.M. Baker, B. Trappmann, S.C. Stapleton, E. Toro, C.S. Chen, Microfluidics embedded within extracellular matrix to define vascular architectures and pattern diffusive gradients, Lab Chip 13 (2013) 3246-3252.

[90] Y. Shin, S. Han, J.S. Jeon, K. Yamamoto, I.K. Zervantonakis, R. Sudo, et al., Microfluidic assay for simultaneous culture of multiple cell types on surfaces or within hydrogels, Nat. Protoc. 7 (2012) 1247-1259.

[91] Y.C. Toh, T.C. Lim, D. Tai, G.F. Xiao, D. van Noort, H.R. Yu, A microfluidic 3D hepatocyte chip for drug toxicity testing, Lab Chip 9 (2009) 2026-2035.

[92] G.M. Price, K.K. Chu, J.G. Truslow, M.D. Tang-Schomer, A.P. Golden, J. Mertz, et al., Bonding of macromolecular hydrogels using perturbants, J. Am. Chem. Soc. 130 (2008). 6664-+.

[93] S. Cosson, S.A. Kobel, M.P. Lutolf, Capturing complex protein gradients on biomimetic hydrogels for cell-based assays, Adv. Funct. Mater. 19 (2009) 3411-3419.

[94] N.D. Dinh, Y.Y. Chiang, H. Hardelauf, J. Baumann, E. Jackson, S. Waide, et al., Microfluidic construction of minimalistic neuronal co-cultures, Lab Chip 13 (2013) 1402-1412.

[95] G.W. Si, W. Yang, S.Y. Bi, C.X. Luo, Q. Ouyang, A parallel diffusion-based microfluidic device for bacterial chemotaxis analysis, Lab Chip 12 (2012) 1389-1394.

[96] B. Carrion, C.P. Huang, C.M. Ghajar, S. Kachgal, E. Kniazeva, N.L. Jeon, et al., Recreating the perivascular niche ex vivo using a microfluidic approach, Biotechnol. Bioeng. 107 (2010) 1020-1028.

[97] S. Ostrovidov, N. Annabi, A. Seidi, M. Ramalingam, F. Dehghani, H. Kaji, et al., Controlled release of drugs from gradient hydrogels for high-throughput analysis of cell-drug interactions, Anal. Chem. 84 (2012) 1302-1309.
[98] F. Piraino, G. Camci-Unal, M.J. Hancock, M. Rasponi, A. Khademhosseini, Multi-gradient hydrogels produced layer by layer with capillary flow and crosslinking in open microchannels, Lab Chip 12 (2012) 659-661.

[99] J. Malda, J. Visser, F.P. Melchels, T. Jungst, W.E. Hennink, W.J.A. Dhert, et al., 25th anniversary article: engineering hydrogels for biofabrication, Adv. Mater. 25 (2013) 5011-5028.

[100] D. Gao, J.J. Liu, H.B. Wei, H.F. Li, G.S. Guo, J.M. Lin, A microfluidic approach for anticancer drug analysis based on hydrogel encapsulated tumor cells, Anal. Chim. Acta 665 (2010) 7-14.

[101] N.S. Bhise, J. Ribas, V. Manoharan, Y.S. Zhang, A. Polini, S. Massa, et al., Organon-a-chip platforms for studying drug delivery systems, J. Control. Release 190 (2014) 82-93.

[102] S.N. Bhatia, D.E. Ingber, Microfluidic organs-on-chips, Nat. Biotechnol. 32 (2014) 760-772.

[103] R.W. Muthard, S.L. Diamond, Side view thrombosis microfluidic device with controllable wall shear rate and transthrombus pressure gradient, Lab Chip 13 (2013) 1883-1891.

[104] M. Li, N.A. Hotaling, D.N. Ku, C.R. Forest, Microfluidic thrombosis under multiple shear rates and antiplatelet therapy doses, PLoS One (2014) 9.

[105] S. Chung, R. Sudo, V. Vickerman, I. Zervantonakis, R. Kamm, Microfluidic platforms for studies of angiogenesis, cell migration, and cell-cell interactions, Ann. Biomed. Eng. 38 (2010) 1164-1177.

[106] E.W.K. Young, Advances in microfluidic cell culture systems for studying angiogenesis, J. Lab. Autom. 18 (2013) 427-436.

[107] S.H. Lim, C. Kim, A.R. Aref, R.D. Kamm, M. Raghunath, Complementary effects of ciclopirox olamine, a prolyl hydroxylase inhibitor and sphingosine 1phosphate on fibroblasts and endothelial cells in driving capillary sprouting, Integr. Biol.-UK 5 (2013) 1474-1484.

[108] K.H. Wong, J.M. Chan, R.D. Kamm, J. Tien, Microfluidic models of vascular functions, Annu. Rev. Biomed. Eng. 14 (2012) 205-230.

[109] R. Booth, H. Kim, Characterization of a microfluidic in vitro model of the blood-brain barrier ([small mu]BBB), Lab Chip 12 (2012) 1784-1792.

[110] B. Prabhakarpandian, M.-C. Shen, J.B. Nichols, I.R. Mills, M. SidorykWegrzynowicz, M. Aschner, et al., SyM-BBB: a microfluidic blood brain barrier model, Lab Chip 13 (2013) 1093-1101.

[111] L.M. Griep, F. Wolbers, B. de Wagenaar, P.M. ter Braak, B.B. Weksler, I.A. Romero, et al., BBB on chip: microfluidic platform to mechanically and biochemically modulate blood-brain barrier function, Biomed. Microdevices 15 (2013) 145-150.

[112] Y.H. Hsu, M.L. Moya, C.C.W. Hughes, S.C. George, A.P. Lee, A microfluidic platform for generating large-scale nearly identical human microphysiological vascularized tissue arrays, Lab Chip 13 (2013) 29902998.

[113] A. Hasan, A. Paul, N.E. Vrana, X. Zhao, A. Memic, Y.S. Hwang, et al., Microfluidic techniques for development of 3D vascularized tissue, Biomaterials 35 (2014) 7308-7325.

[114] J. Friedrich, R. Ebner, L.A. Kunz-Schughart, Experimental anti-tumor therapy in 3-D: spheroids-old hat or new challenge?, Int J. Radiat. Biol. 83 (2007) $849-871$.

[115] F. Hirschhaeuser, H. Menne, C. Dittfeld, J. West, W. Mueller-Klieser, L.A. KunzSchughart, Multicellular tumor spheroids: an underestimated tool is catching up again, J. Biotechnol. 148 (2010) 3-15.

[116] D. Herrmann, J.R.W. Conway, C. Vennin, A. Magenau, W.E. Hughes, J.P. Morton, et al., Three-dimensional cancer models mimic cell-matrix interactions in the tumour microenvironment, Carcinogenesis 35 (2014) 1671-1679.

[117] X. Xu, M.C. Farach-Carson, X. Jia, Three-dimensional in vitro tumor models for cancer research and drug evaluation, Biotechnol. Adv. 32 (2014) 1256-1268.

[118] K. Kwapiszewska, A. Michalczuk, M. Rybka, R. Kwapiszewski, Z. Brzozka, A microfluidic-based platform for tumour spheroid culture, monitoring and drug screening, Lab Chip 14 (2014) 2096-2104.

[119] J. Ruppen, L. Cortes-Dericks, E. Marconi, G. Karoubi, R.A. Schmid, R. Peng, et al., A microfluidic platform for chemoresistive testing of multicellular pleural cancer spheroids, Lab Chip 14 (2014) 1198-1205.

[120] O. Frey, P.M. Misun, D.A. Fluri, J.G. Hengstler, A. Hierlemann, Reconfigurable microfluidic hanging drop network for multi-tissue interaction and analysis, Nat. Commun. (2014) 5.

[121] D. Majumdar, Y. Gao, D. Li, D.J. Webb, Co-culture of neurons and glia in a novel microfluidic platform, J. Neurosci. Methods 196 (2011) 38-44.

[122] H. Hardelauf, J. Sisnaiske, A.A. Taghipour-Anvari, P. Jacob, E. Drabiniok, U. Marggraf, et al., High fidelity neuronal networks formed by plasma masking with a bilayer membrane: analysis of neurodegenerative and neuroprotective processes, Lab Chip 11 (2011) 2763-2771.

[123] D. Huh, D.C. Leslie, B.D. Matthews, J.P. Fraser, S. Jurek, G.A. Hamilton, et al., A human disease model of drug toxicity-induced pulmonary edema in a lungon-a-chip microdevice, Sci. Transl. Med. (2012) 4.

[124] D. Huh, B.D. Matthews, A. Mammoto, M. Montoya-Zavala, H.Y. Hsin, D.E. Ingber, Reconstituting organ-level lung functions on a chip, Science 328 (2010) 1662-1668.

[125] J.S. Jeon, S. Bersini, M. Gilardi, G. Dubini, J.L. Charest, M. Moretti, et al., Human 3D vascularized organotypic microfluidic assays to study breast cancer cell extravasation, Proc. Natl. Acad. Sci. U.S.A. 112 (2015) 214-219.

[126] A.G. Sciancalepore, F. Sallustio, S. Girardo, L.G. Passione, A. Camposeo, E. Mele, et al., A bioartificial renal tubule device embedding human renal stem/ progenitor cells, PLoS One (2014) 9. 
[127] A. Polini, L. Prodanov, N.S. Bhise, V. Manoharan, M.R. Dokmeci, A Khademhosseini, Organs-on-a-chip: a new tool for drug discovery, Expert Opin. Drug Discovery 9 (2014) 335-352.

[128] D. Huh, G.A. Hamilton, D.E. Ingber, From 3D cell culture to organs-on-chips, Trends Cell Biol. 21 (2011) 745-754.

[129] B. Harink, S. Le Gac, R. Truckenmuller, C. van Blitterswijk, P. Habibovic, Regeneration-on-a-chip? The perspectives on use of microfluidics in regenerative medicine, Lab Chip 13 (2013) 3512-3528.

[130] E.C. Jensen, A.M. Stockton, T.N. Chiesl, J. Kim, A. Bera, R.A. Mathies, Digitally programmable microfluidic automaton for multiscale combinatorial mixing and sample processing, Lab Chip 13 (2013) 288-296.

[131] N.T. Huang, S.C. Truxal, Y.C. Tung, A. Hsiao, S. Takayama, K. Kurabayashi, High-speed tuning of visible laser wavelength using a nanoimprinted grating optical tunable filter, Appl. Phys. Lett. 95 (2009).

[132] T.L. Chen, M. Ciocarlie, S. Cousins, P.M. Grice, K. Hawkins, K. Hsiao, et al., Robots for humanity using assistive robotics to empower people with disabilities, IEEE Robot. Autom. Mag. 20 (2013) 30-39.

[133] S.W. Hu, B.Y. Xu, W.K. Ye, X.H. Xia, H.Y. Chen, J.J. Xu, Versatile microfluidic droplets array for bioanalysis, ACS Appl. Mater. Interfaces 7 (2015) 935-940.

[134] Q.Q. Zhang, S.J. Zeng, J.H. Qin, B.C. Lin, Microfluidic droplet trapping array as nanoliter reactors for gas-liquid chemical reaction, Electrophoresis 30 (2009) 3181-3188.

[135] G.S. Du, J.Z. Pan, S.P. Zhao, Y. Zhu, J.M.J. den Toonder, Q. Fang, Cell-based drug combination screening with a microfluidic droplet array system, Anal. Chem. 85 (2013) 6740-6747

[136] S. Allazetta, T.C. Hausherr, M.P. Lutolf, Microfluidic synthesis of cell-typespecific artificial extracellular matrix hydrogels, Biomacromolecules 14 (2013) 1122-1131.

[137] P. Agarwal, S. Zhao, P. Bielecki, W. Rao, J.K. Choi, Y. Zhao, et al., One-step microfluidic generation of pre-hatching embryo-like core-shell microcapsules for miniaturized 3D culture of pluripotent stem cells, Lab Chip 13 (2013) 4525-4533.

[138] V. Miralles, A. Huerre, H. Williams, B. Fournie, M.C. Jullien, A versatile technology for droplet-based microfluidics: thermomechanical actuation, Lab Chip (2015).

[139] E.J. Griffith, S. Akella, Coordinating multiple droplets in planar array digital microfluidic systems, Int. J. Robot. Res. 24 (2005) 933-949.

[140] D.Q. Jin, Y. Zhu, Q. Fang, Swan probe: a nanoliter-scale and high-throughput sampling interface for coupling electrospray ionization mass spectrometry with microfluidic droplet array and multiwell plate, Anal. Chem. 86 (2014) $10796-10803$.

[141] Y. Su, Y. Zhu, Q. Fang, A multifunctional microfluidic droplet-array chip for analysis by electrospray ionization mass spectrometry, Lab Chip 13 (2013) 1876-1882.

[142] Y. Zhu, H. Chen, G.S. Du, Q. Fang, Microfluidic droplet-array liquid-liquid chromatography based on droplet trapping technique, Lab Chip 12 (2012) 4350-4354.

[143] A.Y. Hsiao, Y.S. Torisawa, Y.C. Tung, S. Sud, R.S. Taichman, K.J. Pienta, et al., Microfluidic system for formation of PC-3 prostate cancer co-culture spheroids, Biomaterials 30 (2009) 3020-3027.

[144] J. Thiele, M. Windbergs, A.R. Abate, M. Trebbin, H.C. Shum, S. Forster, et al, Early development drug formulation on a chip: fabrication of nanoparticles using a microfluidic spray dryer, Lab Chip 11 (2011) 2362-2368.

[145] S.H. Kim, J.W. Kim, D.H. Kim, S.H. Han, D.A. Weitz, Polymersomes containing a hydrogel network for high stability and controlled release, Small 9 (2013) $124-131$.

[146] P.M. Valencia, E.M. Pridgen, M. Rhee, R. Langer, O.C. Farokhzad, R. Karnik Microfluidic platform for combinatorial synthesis and optimization of targeted nanoparticles for cancer therapy, ACS Nano 7 (2013) 10671-10680.

[147] H. Zec, T.D. Rane, T.H. Wang, Microfluidic platform for on-demand generation of spatially indexed combinatorial droplets, Lab Chip 12 (2012) 3055-3062.

[148] A.B. Theberge, E. Mayot, A. El Harrak, F. Kleinschmidt, W.T. Huck, A.D. Griffiths, Microfluidic platform for combinatorial synthesis in picolitre droplets, Lab Chip 12 (2012) 1320-1326.

[149] C.H. Yang, K.S. Huang, P.W. Lin, Y.C. Lin, Using a cross-flow microfluidic chip and external crosslinking reaction for monodisperse TPP-chitosan microparticles, Sens. Actuators, B-Chem. 124 (2007) 510-516.

[150] C.E.Y. Cha, J. Oh, K. Kim, Y.L. Qiu, M. Joh, S.R. Shin, et al., Microfluidics-assisted fabrication of gelatin-silica core-shell microgels for injectable tissue constructs, Biomacromolecules 15 (2014) 283-290.

[151] H. Andrade-Zaldívar, L. Santos, A. De León Rodríguez, Expansion of human hematopoietic stem cells for transplantation: trends and perspectives, Cytotechnology 56 (2008) 151-160.

[152] S. Kedong, F. Xiubo, L. Tianqing, H. Macedo, J. LiLi, F. Meiyun, et al., Simultaneous expansion and harvest of hematopoietic stem cells and mesenchymal stem cells derived from umbilical cord blood, J. Mater. Sci. Mater. Med. 21 (2010) 3183-3193.

[153] M. Buitinga, R. Truckenmüller, M.A. Engelse, L. Moroni, H.W.M. Ten Hoopen, C.A. van Blitterswijk, et al., Microwell scaffolds for the extrahepatic transplantation of islets of langerhans, PLoS One 8 (2013) e64772.

[154] T. Siminiak, M. Kurpisz, Myocardial replacement therapy, Circulation 108 (2003) 1167-1171.

[155] A. Fernandes-Platzgummer, M.M. Diogo, R.P. Baptista, C.L. da Silva, J.M. Cabral, Scale-up of mouse embryonic stem cell expansion in stirred bioreactors, Biotechnol. Prog. 27 (2011) 1421-1432.
[156] S.M. Azarin, S.P. Palecek, Development of scalable culture systems for human embryonic stem cells, Biochem. Eng. J. 48 (2010) 378-384.

[157] J. Carmelo, A. Fernandes-Platzgummer, J.S. Cabral, C. da Silva, Scalable ex vivo expansion of human mesenchymal stem/stromal cells in microcarrier-based stirred culture systems, in: K. Turksen (Ed.), Stem Cells and Good Manufacturing Practices, Springer, New York, 2015, pp. 147-159.

[158] A.A. Tomei, V. Manzoli, C.A. Fraker, J. Giraldo, D. Velluto, M. Najjar, et al., Device design and materials optimization of conformal coating for islets of Langerhans, Proc. Natl. Acad. Sci. U.S.A. 111 (2014) 10514-10519.

[159] Y. Teramura, H. Iwata, Bioartificial pancreas microencapsulation and conformal coating of islet of Langerhans, Adv. Drug Deliv. Rev. 62 (2010) $827-840$.

[160] H.F. Chan, Y. Zhang, Y.P. Ho, Y.L. Chiu, Y. Jung, K.W. Leong, Rapid formation of multicellular spheroids in double-emulsion droplets with controllable microenvironment, Sci. Rep.-UK (2013) 3.

[161] K.A. Hyun, H.I. Jung, Advances and critical concerns with the microfluidic enrichments of circulating tumor cells, Lab Chip 14 (2014) 45-56.

[162] C.A. Bichsel, S. Gobaa, S. Kobel, C. Secondini, G.N. Thalmann, M.G. Cecchini, et al., Diagnostic microchip to assay 3D colony-growth potential of captured circulating tumor cells, Lab Chip 12 (2012) 2313-2316.

[163] B.Y. Zhang, J.V. Green, S.K. Murthy, M. Radisic, Label-free enrichment of functional cardiomyocytes using microfluidic deterministic lateral flow displacement, PLoS One (2012) 7.

[164] A. Tripathi, J. Riddell, N. Chronis, A biochip with a 3D microfluidic architecture for trapping white blood cells, Sens. Actuators, B Chem. 186 (2013) 244-251.

[165] H.W. Wu, X.Z. Lin, S.M. Hwang, G.B. Lee, A microfluidic device for separation of amniotic fluid mesenchymal stem cells utilizing louver-array structures, Biomed. Microdevices 11 (2009) 1297-1307.

[166] C. Chun-Li, C.A. Savran, S. Jalal, D.E. Matei, Micro-aperture chip system for high-throughput immunomagnetic cell detection, Sensors, IEEE (2012) 1-4.

[167] R.M. Cooper, D.C. Leslie, K. Domansky, A. Jain, C. Yung, M. Cho, et al., A microdevice for rapid optical detection of magnetically captured rare blood pathogens, Lab Chip 14 (2014) 182-188.

[168] Q.S. Chen, J. Wu, Y.D. Zhang, Z. Lin, J.M. Lin, Targeted isolation and analysis of single tumor cells with aptamer-encoded microwell array on microfluidic device, Lab Chip 12 (2012) 5180-5185.

[169] J.H. Chung, Y.J. Kim, E. Yoon, Highly-efficient single-cell capture in microfluidic array chips using differential hydrodynamic guiding structures, Appl. Phys. Lett. 98 (2011).

[170] C.X. Luo, H. Li, C.Y. Xiong, X.L. Peng, Q.L. Kou, Y. Chen, et al., The combination of optical tweezers and microwell array for cells physical manipulation and localization in microfluidic device, Biomed. Microdevices 9 (2007) 573-578.

[171] M. Werner, F. Merenda, J. Piguet, R.P. Salathe, H. Vogel, Microfluidic array cytometer based on refractive optical tweezers for parallel trapping, imaging and sorting of individual cells, Lab Chip 11 (2011) 2432-2439.

[172] L.J. Millet, K. Park, N.N. Watkins, K.J. Hsia, R. Bashir, Separating beads and cells in multi-channel microfluidic devices using dielectrophoresis and laminar flow, J. Vis. Exp. (48) (2011), http://dx.doi.org/10.3791/2545.

[173] A. Valero, T. Braschler, N. Demierre, P. Renaud, A miniaturized continuous dielectrophoretic cell sorter and its applications, Biomicrofluidics 4 (2010) 022807.

[174] X. Chen, J.Q. Liu, J. Zhu, Y.F. Sun, J. Fan, Optimization of microfluidic immunomagnetic chip for circulating tumor cell capture, Sens. Mater. 25 (2013) 667-671.

[175] P. Chen, Y.-Y. Huang, K. Hoshino, J.X.J. Zhang, Microscale magnetic field modulation for enhanced capture and distribution of rare circulating tumor cells, Sci. Rep. (2015) 5.

[176] S.N. Wang, X.L. Zhang, W.X. Wang, L.J. Lee, Semicontinuous flow electroporation chip for high-throughput transfection on mammalian cells, Anal. Chem. 81 (2009) 4414-4421.

[177] N. Hu, X.L. Zhang, J. Yang, S.W. Joo, S.Z. Qian, A cell electrofusion microfluidic chip with micro-cavity microelectrode array, Microfluid. Nanofluid. 15 (2013) 151-160.

[178] N. Hu, J. Yang, S.W. Joo, A.N. Banerjee, S. Qian, Cell electrofusion in microfluidic devices: a review, Sens. Actuators, B: Chem. 178 (2013) 63-85.

[179] R.M. Schoeman, E.W.M. Kemna, F. Wolbers, A. van den Berg, High-throughput deterministic single-cell encapsulation and droplet pairing, fusion, and shrinkage in a single microfluidic device, Electrophoresis 35 (2014) 385-392.

[180] C. Wyatt Shields Iv, C.D. Reyes, G.P. Lopez, Microfluidic cell sorting: a review of the advances in the separation of cells from debulking to rare cell isolation, Lab Chip 15 (2015) 1230-1249.

[181] E.N. Zare, M.M. Lakouraj, M. Baghayeri, Electro-magnetic polyfuran $/ \mathrm{Fe}_{3} \mathrm{O}_{4}$ nanocomposite: synthesis, characterization, antioxidant activity, and its application as a biosensor, Int. J. Polym. Mater. Polym. 64 (2015) 175-183.

[182] Z. Bagheryan, J.B. Raoof', R. Ojani, Development of a new gquadruplex biosensor with the functionalized SBA-15-Au nanoparticles: a platform for selecting gquadruplex-binding ligands, Sens. Actuators, B: Chem. 213 (2015) 124-130.

[183] P. Guo, E.W. Hall, R. Schirhagl, H. Mukaibo, C.R. Martin, R.N. Zare, Microfluidic capture and release of bacteria in a conical nanopore array, Lab Chip 12 (2012) 558-561.

[184] U. Shimanovich, I. Efimov, T.O. Mason, P. Flagmeier, A.K. Buell, A. Gedanken, et al., Protein microgels from amyloid fibril networks, ACS Nano 9 (2015) 4351. 
[185] G. Castillo, K. Spinella, A. Poturnayova, M. Snejdarkova, L. Mosiello, T. Hianik, Detection of aflatoxin B-1 by aptamer-based biosensor using PAMAM dendrimers as immobilization platform, Food Control 52 (2015) 9-18.

[186] S. Choi, J.K. Park, Microfluidic system for dielectrophoretic separation based on a trapezoidal electrode array, Lab Chip 5 (2005) 1161-1167.

[187] L. Zou, C.S. Wu, Q. Wang, J. Zhou, K.Q. Su, H.B. Li, et al., An improved sensitive assay for the detection of PSP toxins with neuroblastoma cell-based impedance biosensor, Biosens. Bioelectron. 67 (2015) 458-464.

[188] G. Catanante, L. Espin, J.L. Marty, Sensitive biosensor based on recombinant PP1 alpha for microcystin detection, Biosens. Bioelectron. 67 (2015) 700707.

[189] J. Cecchetto, F.C. Carvalho, A. Santos, F.C.B. Fernandes, P.R. Bueno, An impedimetric biosensor to test neat serum for dengue diagnosis, Sens. Actuators, B: Chem. 213 (2015) 150-154.

[190] X.Y. Ding, P. Li, S.C.S. Lin, Z.S. Stratton, N. Nama, F. Guo, et al., Surface acoustic wave microfluidics, Lab Chip 13 (2013) 3626-3649.

[191] X.L. Wang, S.X. Chen, M. Kong, Z.K. Wang, K.D. Costa, R.A. Li, et al., Enhanced cell sorting and manipulation with combined optical tweezer and microfluidic chip technologies, Lab Chip 11 (2011) 3656-3662.

[192] Q. Hamid, C. Wang, J. Snyder, S. Williams, Y. Liu, W. Sun, Maskless fabrication of cell-laden microfluidic chips with localized surface functionalization for the co-culture of cancer cells, Biofabrication 7 (2015) 015012.

[193] A.I. Shallan, P. Smejkal, M. Corban, R.M. Guijt, M.C. Breadmore, Cost-effective three-dimensional printing of visibly transparent microchips within minutes, Anal. Chem. 86 (2014) 3124-3130.

[194] J.L. Erkal, A. Selimovic, B.C. Gross, S.Y. Lockwood, E.L. Walton, S. McNamara, et al., 3D printed microfluidic devices with integrated versatile and reusable electrodes, Lab Chip 14 (2014) 2023-2032.

[195] Y. Zhang, Y. Yu, I.T. Ozbolat, Direct bioprinting of vessel-like tubular microfluidic channels, J. Nanotechnol. Eng. Med. 4 (2013) 0210011-210017.

[196] J.E. Snyder, Q. Hamid, C. Wang, R. Chang, K. Emami, H. Wu, et al., Bioprinting cell-laden matrigel for radioprotection study of liver by pro-drug conversion in a dual-tissue microfluidic chip, Biofabrication 3 (2011).

[197] H.C. Shum, A. Bandyopadhyay, S. Bose, D.A. Weitz, Double emulsion droplets as microreactors for synthesis of mesoporous hydroxyapatite, Chem. Mater. 21 (2009) 5548-5555.
[198] Y. Kitagawa, Y. Naganuma, Y. Yajima, M. Yamada, M. Seki, Patterned hydroge microfibers prepared using multilayered microfluidic devices for guiding network formation of neural cells, Biofabrication 6 (2014).

[199] F. Stumpf, J. Schoendube, A. Gross, C. Rath, S. Niekrawietz, P. Koltay, et al., Single-cell PCR of genomic DNA enabled by automated single-cell printing for cell isolation, Biosens. Bioelectron. 69 (2015) 301-306.

[200] J. Schoendube, A. Yusof, K. Kalkandjiev, R. Zengerle, P. Koltay, Wafer level fabrication of single cell dispenser chips with integrated electrodes for particle detection, J. Micromech. Microeng. (2015) 25.

[201] A. Gross, J. Schöndube, S. Niekrawitz, W. Streule, L. Riegger, R. Zengerle, et al. Single-cell printer: automated, on demand, and label free, J. Lab. Autom. 18 (2013) 504-518.

[202] T. Kawahara, S. Ohashi, M. Hagiwara, Y. Yamanishi, F. Arai, Air-flow-based single-cell dispensing system, Adv. Rob. 26 (2012) 291-306.

[203] L. Feng, Y. Sun, C. Ohsumi, F. Arai, Accurate dispensing system for single oocytes using air ejection, Biomicrofluidics 7 (2013) 054113.

[204] A. van Reenen, A.M. de Jong, J.M.J. den Toonder, M.W.J. Prins, Integrated labon-chip biosensing systems based on magnetic particle actuation - a comprehensive review, Lab Chip 14 (2014) 1966-1986.

[205] O. Strohmeier, S. Keil, B. Kanat, P. Patel, M. Niedrig, M. Weidmann, et al. Automated nucleic acid extraction from whole blood, B. subtilis, E. coli and Rift Valley fever virus on a centrifugal microfluidic LabDisk, RSC Adv. 5 (2015) 32144-32150.

[206] D. Jens, H. Stefan, L. Sascha, P. Sarah, S. Felix von, Z. Roland, The centrifugal microfluidic Bio-Disk platform, J. Micromech. Microeng. 17 (2007) S103.

[207] R. Gorkin, J. Park, J. Siegrist, M. Amasia, B.S. Lee, J.-M. Park, et al., Centrifugal microfluidics for biomedical applications, Lab Chip 10 (2010) 1758-1773.

[208] M. Keller, J. Naue, R. Zengerle, F. von Stetten, U. Schmidt, Automated forensic animal family identification by nested pcr and melt curve analysis on an offthe-shelf thermocycler augmented with a centrifugal microfluidic disk segment, PLoS One 10 (2015) e0131845.

[209] M.A. Witek, M.L. Hupert, D.S.W. Park, K. Fears, M.C. Murphy, S.A. Soper, 96 Well polycarbonate-based microfluidic titer plate for high-throughput purification of DNA and RNA, Anal. Chem. 80 (2008) 3483-3491.

[210] P.J. Lee, N. Ghorashian, T.A. Gaige, P.J. Hung, Microfluidic system for automated cell-based assays, J. Assoc. Lab. Autom. 12 (2007) 363-367. 